\title{
O desmatamento da Amazônia brasileira sob o prisma da pecuária: a degradação dos recursos hídricos no contexto da região norte de Mato Grosso
}

\author{
Deforestation in the Brazilian Amazon from the perspective of cattle ranching: the degradation of \\ water resources in the context of the northern region of Mato Grosso
}

La deforestación de la Amazonia brasileña desde el punto de vista de la ganadería: la degradación de los recursos hídricos en el contexto de la región norte de Mato Grosso

Recebido: 09/08/2021 | Revisado: 18/08/2021 | Aceito: 20/08/2021 | Publicado: 22/08/2021

Marisa Regina Kohler
ORCID: https://orcid.org/0000-0003-2183-8673
Universidade do Estado do Mato Grosso, Brasil
E-mail: marisa.kohler@ @unemat.br
Aumeri Carlos Bampi
ORCID: https://orcid.org/0000-0002-3410-9376
Universidade do Estado do Mato Grosso, Brasil
E-mail: aumeri@ @unemat.br
Carlos Alberto Franco da Silva
ORCID: https://orcid.org/0000-0002-3198-2188
Universidade Federal Fluminense
E-mail: carlosfds1963@ gmail.com
Almir Arantes
ORCID: https://orcid.org/0000-0003-4793-2908
Universidade do Estado do Mato Grosso, Brasil
E-mail: almir.unemat@ gmail.com
Waldir José Gaspar
ORCID: https://orcid.org/0000-0001-8758-4333
Faculdade de Belas Artes de São Paulo, Brasil
Universidade Federal de Mato Grosso, Brasil
E-mail: gasparhome@ terra.com.br

\begin{abstract}
Resumo
O estudo objetivou estabelecer uma relação entre o processo de desmatamento, a expansão da pecuária na Amazônia brasileira e a degradação dos corpos hídricos. A investigação seguiu uma abordagem qualitativa, com procedimentos da revisão bibliográfica e levantamento de dados de desmatamento e da produção pecuária bovina dos estados da Amazônia Legal, como forma de contextualizar o encadeamento dos projetos desenvolvimentistas desde a década de 1970. Com foco em área localizada no bioma Amazônia, no norte de Mato Grosso, foram levantadas informações dos municípios da macrorregião, denominada pelo Instituto Mato-Grossense de Economia Agropecuária, como Norte 2. Com base nos dados do PRODES e IBGE-SIDRA, no período entre 1985 a 2020, foi observado que a maior parte das áreas desmatadas foi ocupada com pecuária bovina, sendo, portanto, o maior vetor de desmatamento. A supressão da floresta e o manejo inadequado do solo comprometem diretamente os recursos hídricos. Além disso, sem o respeito à legislação ambiental de preservação das Áreas de Proteção Permanente (APPs), a atividade ocasionou intensa degradação ambiental, atingindo sobremaneira as matas ciliares por derrubadas e queimadas, o que implicou na vitalidade (quantidade e qualidade da água) das nascentes, córregos e rios e perda da função ecológica.
\end{abstract}

Palavras-chave: Amazônia norte mato-grossense; Desmatamento; Pecuária bovina; Escassez hídrica.

\begin{abstract}
The study aimed to establish a relationship between the deforestation process, the expansion of cattle ranching in the Brazilian Amazon and the degradation of water bodies. The investigation followed a qualitative approach, with bibliographic review procedures and data survey on deforestation and cattle ranching in the states of the Legal Amazon, as a way of contextualizing the chain of developmental projects since the 1970s. Focusing on an area located in the Amazon biome, in the north of Mato Grosso, information was collected from municipalities in the macroregion, named by the Mato Grosso Institute of Agricultural Economics, as North 2. Based on data from PRODES and IBGE-SIDRA, in the period between 1985 and 2020, it was observed that most of the deforested areas were occupied by cattle ranching, being, therefore, the largest vector of deforestation. The suppression of the forest and the inadequate management of the soil directly compromise water resources. In addition, without respecting the environmental legislation for the preservation of Permanent Protection Areas (APPs), the activity caused intense
\end{abstract}


environmental degradation, greatly affecting the riparian forests by felling and burning, which implied in the vitality (quantity and quality of water) of the springs, streams and rivers and loss of ecological function.

Keywords: Northern Mato Grosso Amazon; Deforestation; Cattle ranching; Water scarcity.

\section{Resumen}

El estudio establece una relación entre el proceso de deforestación, la expansión de la ganadería en la Amazonia brasileña y la degradación de las masas de agua. La investigación siguió un enfoque cualitativo, con procedimientos de revisión bibliográfica y relevamiento de datos de deforestación y producción ganadera en los Estados de la Amazonia Legal, como forma de contextualizar la cadena de proyectos de desarrollo desde la década de 1970. Centrándonos en un área localizada en el bioma amazónico, en el norte de Mato Grosso, se recopiló información de los municipios de la región macro denominada por el Instituto de Economía Agrícola de Mato Grosso como Norte 2. A partir de los datos del PRODES y del IBGE-SIDRA, en el período de 1985 a 2020, se observó que la mayor parte de las áreas deforestadas fueron ocupadas por la ganadería, siendo por tanto el mayor vector de deforestación. La supresión del bosque y la gestión inadecuada del suelo compromete directamente los recursos hídricos. Además, sin respetar la legislación ambiental sobre la preservación de las zonas de protección permanente, la actividad ha provocado una intensa degradación ambiental, afectando especialmente a los bosques de ribera mediante la tala y la quema, lo que implicó en la vitalidad (cantidad y calidad del agua) de manantiales, arroyos y ríos y la pérdida de la función ecológica.

Palabras clave: Amazonía norte mato-grossense; Deforestación; Ganadería; Escasez de agua.

\section{Introdução}

A Amazônia brasileira tem passado, nos últimos 50 anos, por profundas transformações socioprodutivas que resultam em passivos socioambientais e conflitos territoriais entre racionalidades distintas na relação homem e natureza. A partir de 1964, a geopolítica de inserção do território na Doutrina de Segurança Nacional dos governos militares inscreveria um cenário de integração competitiva do bioma como fronteira de recursos no sistema de produção de commodities minerais e agropecuárias dos mercados globais. Para fins de modernização conservadora e autoritária do espaço pouco sintonizado com a economia do país e de manutenção das taxas de crescimento econômico, diante da crise energética mundial e de transformação do padrão fordista-keynesiano de acumulação capitalista, a proposta foi a integração econômica. A fronteira de recursos era acionada pela projeção do vetor de acumulação urbano-industrial, dando amparo à expansão capitalista à região, conforme assinala Becker (2005).

A colonização privada e oficial, a financeirização do território e a constituição de redes técnicas estavam a serviço da formação de um mercado regional de exploração mineral, agropecuária e definição da Zona Franca de Manaus, nas quais as frentes de trabalho seriam aproveitadas. A natureza urbana da fronteira na Amazônia sinalizava para um urbanismo rural dos projetos de colonização e urbanização ao longo dos eixos rodoviários, resultando em um intenso movimento de populações. Apoiava-se ainda na implantação de redes de energia e de comunicações e de próteses industriais. Sob a tutela de um padrão de acumulação fordista-keynesiano-metropolitano, o Estado brasileiro foi o ator por excelência na inserção da Amazônia na divisão regional do trabalho do país e na divisão internacional do trabalho. (Soares Filho, 1998; Oliveira, 2016).

Ao se afirmar como fronteira de recursos, a exploração predatória e autoritária do subsolo e do bioma promoveu conflitos por terra e território e alterou sobremaneira as bases ecológico-culturais de diversos grupos sociais pré-existentes. A intensa transformação socioespacial e a nova configuração econômico-territorial determinada pelo padrão de acumulação apoiado no subsolo-estrada-terra firme resultou em desmatamento do bioma, expansão urbana, conflitos fundiários, formação de polos minero-industriais, Zona Franca de Manaus, exploração ilegal da madeira, metropolização e expansão da atividade agropecuária, dentre outros (Fearnside, 2005; Fearnside, 2020). 
Entre as atividades elencadas, a expansão dos projetos agropecuários tornou-se a principal razão do desmatamento do bioma. O chamado arco do povoamento nas bordas da Amazônia articula-se ao arco do desmatamento, em que uma rede de núcleos urbanos, posteriormente transformados em cidades sedes de municípios desmembrados, deu suporte ao processo de apropriação do território-ambiente. Nesse cenário, a atuação de grileiros, das madeireiras, dos pecuaristas, da exploração mineral e a abertura de pequenas hidrelétricas passaram a definir as principais razões dos conflitos no campo nas diversas realidades socioambientais amazônicas, na última década, conforme dados do Relatório Conflitos no Campo Brasil 2020, da Comissão Pastoral da Terra (CPT). Os conflitos por conta da mineração, exploração ilegal de madeira, agronegócio de grãos e carne situam-se como importantes vetores de passivos ambientais (CPT, 2020).

$\mathrm{Na}$ zona da Amazônia Meridional norte mato-grossense, a problemática da conservação dos recursos hídricos manifesta-se, sobretudo nos termos da emergência do vetor tecnoeco[lógico] de apropriação capitalista como fronteira natural nos termos de Becker (2005), a partir da visibilidade político-ideológica do paradigma do desenvolvimento sustentável ambientalmente. Dentre as ameaças aos recursos hídricos, destaca-se o desmatamento decorrente do avanço do modelo de pecuária extensiva, segundo o INPE (Brasil, 2020).

Assim, é nesse ponto que se situa a definição do objeto de estudo: De que modo a expansão da pecuária na Amazônia coloca-se como ameaça à conservação dos recursos hídricos regionais? De posse de uma questão central, o estudo volta-se para a sinalização da problemática na região do norte mato-grossense, espaço de intensa incorporação de áreas à produção de commodities agrícolas e agropecuárias na Amazônia brasileira.

\section{Metodologia}

A fim de responder à questão central formulada e atender ao objetivo específico, a metodologia subscreve uma abordagem qualitativa que utiliza a revisão bibliográfica da temática e o levantamento de dados sobre o desmatamento e a expansão da pecuária bovina na Amazônia Legal. Para tanto, foram coletados os dados de identificação do percentual de desmatamento (área desmatada de floresta) a partir do sistema PRODES, relativos ao período compreendido entre 1985 a 2020, bem como de estudos que apontam impactos relativos à questão hidrológica na Amazônia. Foram analisados ainda os dados da Produção da Pecuária Municipal (PPM), relativos ao número de cabeças bovinas presentes nos nove estados da Amazônia Legal, no período de 1985 a 2020 (IBGE, 2021), uma vez que é preciso compreender a questão da dimensão da pecuária na Amazônia. Os dados do PRODES e do IBGE, entre outros, foram comparados de modo a legitimar a tese de que os processos de desmatamento e a produção bovina estão intrinsecamente relacionados e configuram-se como os maiores vetores de degradação e destruição da Floresta Amazônica e das Áreas de Preservação Permanente (APPs) e impactam os recursos hídricos e a biodiversidade.

Em termos do recorte do norte mato-grossense, a separação do estado de Mato Grosso em macrorregiões segue dados do Instituto Mato-Grossense de Economia Agropecuária (IMEA, 2010), entidade privada sem fins lucrativos do sistema FAMATO (Federação da Agricultura e Pecuária do Estado de Mato Grosso), em parceria com a Associação dos Produtores de Soja e Milho (APROSOJA), Associação dos Produtores de Algodão (AMPA) e Associação dos Criadores de Mato Grosso (ACRIMAT). Para fins de dados, vale ainda lembrar que o Instituto Mato-Grossense de Economia Agropecuária (IMEA) é ligado à Confederação da Agricultura e Pecuária do Brasil (CNA). O Instituto realiza estudos e projetos socioeconômicos e ambientais em todo o território mato-grossense, a partir de um sistema de coleta, processamento e análise de dados, e produz informações estratégicas do agronegócio para as entidades mantenedoras (IMEA, 2010). Os limites geográficos da área de estudo envolvem a Macrorregião Norte de Mato Grosso em destaque na Figura 1. 


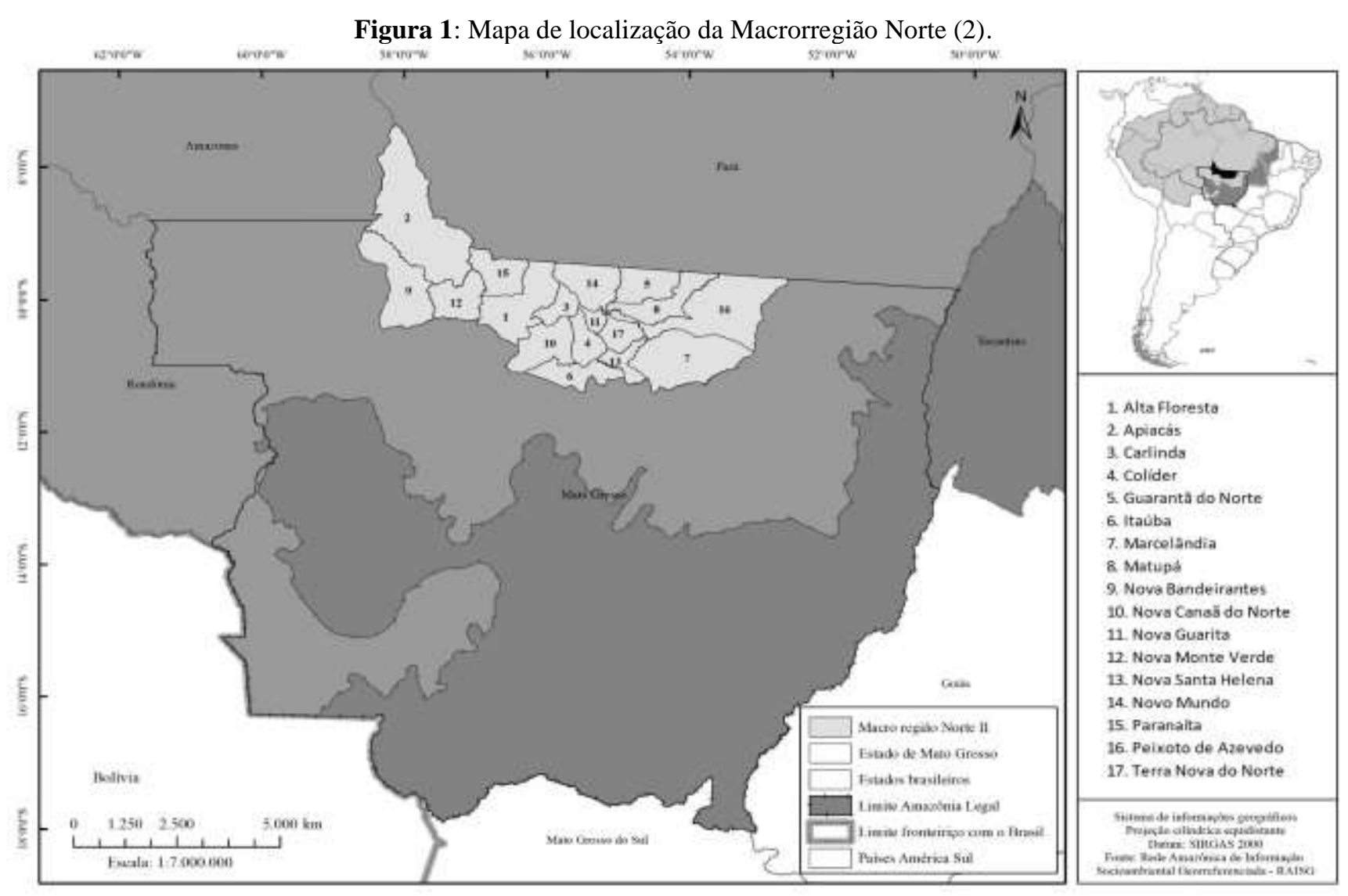

Fonte: Thales Ernildo Lima (2020).

A Macrorregião Norte 2 está inserida no bioma Amazônia e sua cobertura original era de florestas e savanas densas. A pecuária bovina é a principal atividade econômica da região, executada a partir de uma rede técnica de cidades que constituem ferramenta de apoio produtivo no território em questão (IMEA, 2010).

Destarte, para fins de estrutura do artigo, inscrevem-se três partes que se articulam entre si. Na primeira delas, situa-se a dimensão dos recursos hídricos da Amazônia. Na segunda, o estudo se volta para o avanço da pecuária e sua relação com o desmatamento do bioma. Na última parte, a região norte do Mato Grosso apresenta-se como recorte territorial da relação entre pecuária, desmatamento e implicações aos recursos hídricos.

\section{Resultados e discussões}

\subsection{A dimensão geográfica dos recursos hídricos da Amazônia}

A Amazônia sul-americana (Figura 2) engloba a Floresta Amazônica, região de 7,8 milhões de km², compartilhada pela Bolívia (5,31\%), Brasil (67,98\%), Colômbia (6,40\%), Equador (1,55\%), Guiana (2,87\%), Peru (10,14\%), Suriname $(2,18 \%)$, Venezuela $(2,45 \%)$ e Guiana Francesa (1,12\%). Nela vivem 33 milhões de habitantes, incluindo 1,5 milhão de indígenas (Aragón, 2018; Costa, 2020).

Os limites da Amazônia Legal e da região hidrográfica amazônica são diferentes. A região hidrográfica amazônica compreende as áreas que pertencem aos estados do Acre, Amapá, Amazonas, Mato Grosso, Pará, Rondônia e Roraima, com uma área um pouco superior a quatro milhões de $\mathrm{km}^{2}$, excluindo o estado do Tocantins e parte do Maranhão. A Amazônia constitui-se um espaço vital do planeta por possuir o maior estoque de recursos estratégicos (água, biodiversidade, minerais, entre outros), estabelecendo uma realidade geopolítica que exige maior presença do Estado no que tange ao seu crescimento 
econômico, ao desenvolvimento sustentável e à soberania nacional na região (Amin, 2015).

Figura 2: Mapa de delimitação da Panamazônia, Amazônia Legal, Bacia Hidrográfica Amazônica.



Fonte: Thales Ernildo Lima (2020).

A Agência Nacional de Águas (ANA) considera que o Brasil possui cerca de 12\% da disponibilidade de água doce do planeta, tanto superficiais como subterrâneas. Nesse cenário, a Amazônia assume papel de destaque na geografia física brasileira, sobretudo no que diz respeito aos maiores aquíferos do mundo.

O aquífero Guarani, com volume de água de 45 mil quilômetros cúbicos, a maior parte no subsolo brasileiro; e o aquífero Alter-do-Chão, com um volume de água de 86 mil quilômetros cúbicos, localizado nos estados do Amazonas, Pará e Amapá. Nesse contexto de riqueza hídrica, o rio Amazonas, com mais de três mil afluentes, assume posição privilegiada dentro da dimensão geopolítica de utilização e preservação dos recursos naturais do planeta (Amin, 2015, p. 31).

Independentemente da oferta considerável de água, a distribuição não é naturalmente igual em todas as regiões do país, visto que 72\% encontram-se na Região Amazônica, 16\% no Centro-Oeste, 8\% no Sul e no Sudeste e 4\% no Nordeste (Brasil, 2019). Na Amazônia, está localizada a maior bacia hidrográfica do mundo, com mais de sete milhões de $\mathrm{km}^{2}$, abrigando diversos rios, com destaque ao Amazonas (com $7.062 \mathrm{~km}$ ), reconhecido internacionalmente como o de maior comprimento, o mais caudaloso, largo e profundo. Com o nome de Solimões, esse rio nasce a 5.170m de altitude nos Andes peruanos e passa por uma vasta planície, desaguando no Oceano Atlântico (Silva, 2015).

Nessa bacia, encontra-se a Floresta Amazônica, um dos ecossistemas mundiais mais importantes com papel significativo no sistema de regulação dos ciclos hídricos locais, regionais e planetário. As florestas tropicais da América do Sul estão entre os mais densos, diversos e complexos biomas terrestres no planeta (Nobre, 2018; Walker et al., 2019). Na medida 
em que a ocupação produtiva da Amazônia resulta em mudanças climáticas globais, a atenção mundial sobre os destinos dessa região aumenta. Nesse sentido, abrem-se questionamentos sobre até que ponto a soberania dos países amazônicos pode ser questionada em prol do bem comum e/ou do equilíbrio ambiental do planeta (Aragón, 2018; Putti, 2019).

Ao concentrar $8 \%$ de toda a água doce superficial mundial, a abundância de água torna-se um diferencial para os países que dela dispõem, representando uma vantagem competitiva que depende da capacidade de combinar capital, ciência e tecnologia com os fartos recursos hídricos do território (Barros e Amin, 2007). Esse diferencial moldou a cultura da sociedade com a água, estabelecendo um senso comum de abundância de modo que grandes extensões territoriais fossem destinadas à agropecuária e mineração, à geração de energia hidrelétrica e ao consumo urbano-industrial. O resultado da ausência de manejo ecológico da floresta tem sido a degradação ambiental e diminuição dos recursos hídricos (Scantimburgo, 2016).

A destruição via desmatamentos e queimadas da floresta tropical da Amazônia, nas últimas cinco décadas, ocorre por meio das políticas de consolidação nacional dos projetos urbano-industriais, minerais e de intensificação e mercantilização da agropecuária. A problemática do desmatamento das florestas e dos impactos no regime hidrológico das chuvas e ao clima da Amazônia, assim como a preservação da biodiversidade e da água, vem sendo palco de diversos debates nacionais e internacionais nos quais muitos pesquisadores evidenciam a possibilidade de a floresta ser substituída por uma savana tropical (Walker et al., 2019). Nobre et al. (2016) explicitam que:

Uma série de grandes fatores de mudança ambiental estão operando simultaneamente e interagindo de forma não linear na Amazônia, a saber, mudanças no uso da terra e mudanças climáticas devido ao aquecimento global e ao desmatamento, que podem, por sua vez, induzir maior frequência de eventos climáticos extremos e de incêndios em vegetação, aumentando a exposição e vulnerabilidade das florestas tropicais (2016. p. 2).

Os autores Nobre et al. (2016) alertam ainda que a Amazônia pode ter dois pontos de inflexão: 1) a perda de biodiversidade e 2) o desmatamento continuado (superior a 40\%). Assim, evidenciam-se altos riscos de uma mudança irreversível das florestas tropicais, com o aumento de $4^{\circ} \mathrm{C}$ de aquecimento da temperatura global que, em consequência, poderá ocasionar a "savanização", principalmente no sul e leste da Amazônia.

Outro fator que tem um potencial degradante é a associação sinérgica entre secas severas, desmatamento e incêndios na Floresta Amazônica. A capacidade das florestas de manter altas taxas de evapotranspiração durante os períodos de baixa precipitação é a resposta da floresta à seca. Todavia, é importante compreender os aspectos que influenciam a transição da estação seca para a chuvosa. Nobre et al., (2016) relatam que:

Um conjunto de fatores geográficos, geomorfológicos e climáticos torna a bacia amazônica uma área com alta precipitação. A precipitação média anual em toda a bacia é da ordem de $2.200 \mathrm{~mm}$, variando de $3.000 \mathrm{~mm}$ no Oeste, devido à influência dos Andes, a valores em torno de $1.700 \mathrm{~mm}$ no sudeste da bacia, áreas de intenso uso do solo e mudança da cobertura da terra, conhecida como "arco do desmatamento". As altas taxas de precipitação são mantidas tanto pelos fluxos de umidade da evaporação no Oceano Atlântico tropical quanto pela reciclagem da evapotranspiração da floresta $(2016$, p. 2).

A conversão das florestas para pastagens tem ocasionado um aumento de cerca de $25 \%$ na temperatura média de superfície e uma diminuição de $30 \%$ da evapotranspiração anual, $25 \%$ da precipitação e $20 \%$ do escoamento superficial, ocorrendo o aumento da duração da estação seca na metade sul da bacia amazônica, de acordo com estudos de Nobre (2018).

Segundo Davidson et al. (2012), a convecção atmosférica e a precipitação são impulsionadas pelos fluxos de energia e água da superfície da Terra. A diminuição significativa na precipitação em toda a bacia pode ocorrer devido à diminuição na evapotranspiração com o transporte de vapor d'água resultante a favor do vento; e à diminuição da rede de energia solar absorvida e consequente enfraquecimento geral do sistema de baixa pressão em escala continental que impulsiona a precipitação sobre a bacia: 
$\mathrm{O}$ ar acima das áreas desmatadas aquece mais rapidamente e tende a subir e atrair o ar úmido da floresta circundante, criando assim chamadas de 'brisas da vegetação'. Isso diminui as chuvas sobre a floresta, enquanto aumenta a nebulosidade, a chuva e as tempestades sobre as pastagens. Essas mudanças também afetam a disponibilidade de água e luz e a absorção das florestas remanescentes, mas esses efeitos ainda não estão bem quantificados (Davidson et al., 2012, p. 324).

As precipitações em áreas desmatadas escoam rapidamente, podendo ocorrer a redução ou interrupção do fluxo dos cursos d'água que são importantes para o funcionamento do ecossistema natural dos corpos hídricos. Assim como podem ocasionar a perda de produtividade por meio da erosão, compactação e exaustão dos nutrientes do solo. Segundo Fearnside (2005):

A produtividade agrícola cai na medida em que a qualidade do solo piora, embora um patamar mais baixo de produtividade possa ser mantido por sistemas tais como a alternância de cultivo. A adição contínua de cal, adubo e nutrientes pode conter a degradação, mas as limitações de recursos físicos e econômicos tornam o uso desses produtos inefetivo para grandes áreas longe dos mercados urbanos (2005, p. 117).

Os processos de desmatamento e queimadas no seio da base técnica da agricultura e a criação de gado podem ocasionar um período de seca prolongado, de modo a alterar a época de plantio e colheita, assim como proporcionar a falta de água para a dessedentação animal. Dessa forma, a agricultura e pecuária intensiva, a falta de ordenamento territorial, a monocultura de certas espécies e a introdução de espécies exóticas para cultivo são alguns dos fatores que afetam a biodiversidade da Amazônia.

Segundo estudos de Fearnside (2005) e Davidson et al. (2012), os incêndios na Floresta Amazônica tendem a aumentar a mortalidade de árvores e cipós, as árvores grandes geralmente são mais bem adaptadas para sobreviver ao fogo, mas tendem a ser as primeiras a sofrer com a seca. Embora os caules sobreviventes possam se beneficiar do pulso inicial de nutrientes liberados pelo fogo e da competição reduzida, a mortalidade induzida pelo fogo reduz a cobertura geral do dossel, a biomassa e a riqueza de espécies.

O declínio da diversidade de espécies vegetais também reduz a abundância de frutas e invertebrados, alterando o suprimento alimentar de pássaros e outros animais. O fogo pode modificar a estrutura, a composição e funcionamento da vegetação, e favorecer o surgimento de espécies mais inflamáveis (por exemplo, gramíneas), levando a um ecossistema mais semelhante ao da savana (Davidson et al., 2012; Walker et al., 2019).

As queimadas provocam a transformação dos padrões naturais dos ciclos biogeoquímicos, importantes na fertilização dos solos. A perda de nitrogênio $(\mathrm{N})$ durante a queima pós-desmatamento altera os padrões naturais de limitação de fósforo (P) em solos altamente intemperizados. Esses minerais são de extrema importância na regeneração das florestas secundárias que são importantes sumidouros de carbono (fotossíntese), conforme destacam Davidson e Martinelli (2009). As perdas são mais comuns onde os estoques de carbono do solo são inicialmente grandes, e os ganhos maiores derivam de práticas de manejo (fertilizantes, rotação do rebanho, prevenção de sobrepastoreio). No entanto, as mutações nos estoques de carbono do solo geralmente são ofuscadas por perdas muito maiores na biomassa das árvores.

Em relação às mudanças nas emissões de gases de efeito estufa, a Floresta Amazônica é fonte natural significativa de metano. A conversão de formações de vegetação nativa em áreas de pastagem e cultivo causa mudanças substanciais nos processos biogeoquímicos, incluindo a troca de $\mathrm{N}_{2} \mathrm{O}$, óxido nítrico $(\mathrm{NO})$ e metano $\left(\mathrm{CH}_{4}\right)$ entre o ecossistema e a atmosfera. $\mathrm{O}$ óxido nitroso é um gás de efeito estufa estável na troposfera que absorve fortemente a radiação infravermelha e possui um longo tempo de permanência na atmosfera, cerca de 120 anos. $\mathrm{O} \mathrm{N}_{2} \mathrm{O}$ atmosférico é produzido principalmente como resultado de processos microbianos nos solos, especialmente pela desnitrificação e nitrificação quando as tensões de oxigênio são baixas. (Bustamante et al., 2009). 
O balanço do carbono de biomassa para a região não se encontra totalmente definido. As fontes líquidas de emissões e absorções de carbono ocorrem quando uma paisagem florestada é substituída por um mosaico de usos da terra (Fearnside, 2005).

Cerca de dois terços podem vir de detritos de folhas e madeira lançados no rio de florestas inundadas, com cerca de um terço produzido por plantas aquáticas (tapetes de gramíneas e outras macrófitas) dentro do rio, e uma pequena fração por algas. Outras fontes possíveis incluem partículas lavadas com partículas de solo e C orgânico e inorgânico dissolvido na água subterrânea. Sabemos muito pouco sobre o orçamento de C das florestas alagadas e matas ciliares, que provavelmente contribuem com C fixo terrestre significativo para riachos e rios (Davidson et al., 2012, p. 326).

Tanto o carbono orgânico quanto o inorgânico dissolvidos podem ser transportados via água subterrânea e por fluxo superficial das florestas de terras altas para florestas ribeirinhas, e o $\mathrm{CO}_{2}$ pode ser perdido da água do rio para a atmosfera. Os estudos em andamento apontam para grandes reservatórios hidrelétricos como uma crescente fonte de metano.

Diante da definição da problemática hídrica do objeto de estudo, o escopo deste artigo se volta para um dos pilares da relação entre desmatamento e questão dos recursos hídricos: a expansão da pecuária na Amazônia. Em síntese, o objetivo principal é analisar o avanço da pecuária bovina e seus impactos no desmatamento, para fins da substituição da floresta tropical pelo pasto.

\subsection{A relação entre desmatamento, pecuária bovina e degradação ambiental}

A Amazônia vem sendo desmatada há décadas, incluindo as formações vegetais florestais e não florestais. Grande parte do bioma tem sido convertida em pastagens, áreas agrícolas e/ou de exploração madeireira, exploração mineral, garimpo, extrativismo vegetal e áreas urbanas. Sob impacto da revolução científico-tecnológica na base socioprodutiva e na valorização econômica dos recursos naturais, como a água, a biodiversidade, a Amazônia se tornou tanto uma fronteira eco[lógica] do planeta como se manteve fronteira de recursos. Assim, dois vetores de transformações capitalistas e impactos socioambientais estão em disputa: o vetor urbano-industrial, notadamente predatório, e o vetor tecnoeco[lógico] de inserção da sociobiodiversidade nos esquemas de acumulação de capital a partir da preservação da floresta em pé e de apropriação dos saberes ecológico-culturais das populações tradicionais (Becker, 2010).

A acentuada demanda econômica externa por matérias-primas básicas, como madeira, carne, grãos e minérios vem exercendo uma forte pressão sobre a região em face do esgotamento de outras áreas do planeta, é expressa por uma retomada do desmatamento, na última década. Dentre as razões, a especulação de terras é um dos fatores que impulsionam o desmatamento para fins de expansão da pecuária bovina na Amazônia. De acordo com o engenheiro agrônomo Marcelo Stabile, pesquisador do Instituto de Pesquisa Ambiental da Amazônia (IPAM), "as pessoas grilam essas terras, desmatam e colocam algumas cabeças de gado, que é a maneira mais barata de ocupá-las”. O próximo passo é conseguir ilegalmente um título de propriedade da terra e vendê-la. Em seguida, os grileiros buscam outro trecho de floresta e, assim, sucessivamente (Costa, 2020).

No Brasil, as medições para analisar o desmatamento e as queimadas florestais consideram sempre a temporada de agosto de um ano a julho do ano seguinte, precisamente pelas variações climáticas do ciclo completo de seca e chuva na Amazônia, oscilando dentro desses parâmetros. Assim sendo, em 2019, mais de 53 mil focos de queimadas foram registrados no Norte do país e em parte do Maranhão. Em 2018, esse número foi de 26,5 mil, segundo o INPE. Tanto as queimadas quanto às diretrizes insensatas tomadas pelo governo brasileiro ganharam as manchetes dos principais portais de notícia do mundo (Putti, 2019).

As queimadas na região Amazônica foram tão intensas que as cinzas chegaram até a cidade de São Paulo. Meteorologistas confirmam que uma frente fria em união a um corredor de fumaça foi a causa do fenômeno. O episódio 
coaduna com os diversos estudos dos pesquisadores que enfatizam a ligação entre a floresta, a umidade do ar e o clima como interações do sistema no Centro-Sul da América do Sul (Nobre, 2018). A nota técnica de pesquisadores do Instituto de Pesquisa Ambiental da Amazônia (IPAM) e da Universidade Federal do Acre aponta que as queimadas estão relacionadas diretamente com o desmatamento:

Os dez municípios amazônicos que mais registraram focos de incêndios foram também os que tiveram maiores taxas de desmatamento. Estes municípios são responsáveis por 37\% dos focos de calor em 2019 e por 43\% do desmatamento registrado até o mês de julho. Esta concentração de incêndios florestais em áreas recém-desmatadas e com estiagem branda representa um forte indicativo do caráter intencional dos incêndios: limpeza de áreas recém-desmatadas. A conexão entre desmatamento e queimadas contraria o argumento de que os focos de incêndio seriam algo natural, decorrente apenas do período de estiagem no Norte do país (Shalders, 2019).

O uso do fogo está direta ou indiretamente ligado às ações de desmatamento da cadeia da grilagem-agronegócio que ocorrem em grandes extensões de terra associadas à expansão da fronteira agrícola. Nesse sentido, culpar as populações tradicionais pelos incêndios florestais não procede, ao contrário do que afirma o presidente do Brasil.

Com um forte discurso responsabilizando os povos da floresta, esse governo demonstra claramente intenções de desviar a atenção a respeito da origem da maior parte dos incêndios florestais, segundo a Comissão Pastoral da Terra. O relatório intitulado Dia do Fogo - 2019, ocorrido no eixo da BR-163 e na rodovia Transamazônica, mostra evidências de que o uso do fogo pelos invasores de terras públicas está sendo utilizado como arma contra povos e comunidades na Amazônia (indígenas e comunidades quilombolas/tradicionais), visto que os grileiros-desmatadores, garimpeiros e madeireiros não hesitam em realizar os ataques ao queimar casas, roças, barracões comunitários e áreas de uso comum, e assim se apropriar das terras, saqueando seus bens naturais, aterrorizando e expulsando-os de seus territórios (CPT, 2020).

Diversas atividades criminosas provocam a degradação da floresta, como o saque com a extração de madeiras implementada pelos madeireiros, o garimpo, sobretudo em terras indígenas e unidades de conservação. Entretanto, é o desmatamento para a atividade pecuária bovina que assume o protagonismo na degradação da região, e tem o estado do Pará e Mato Grosso como campeões nas taxas de desmatamento.

Conforme Kohlhepp (2002, p. 45), a taxa média anual de desmatamento na Amazônia brasileira, entre 1978 e 1988 , foi de cerca de $21 \mathrm{mil} \mathrm{km}$, enquanto no período de 1988/1998 registrou-se $16 \mathrm{mil} \mathrm{km}^{2}$. Os dados de agosto de 1999 a agosto de 2000 chegaram a $19.800 \mathrm{~km}^{2}$, concentrados nos estados do Mato Grosso (40\%) e Pará (30\%). As informações corroboram com as do gráfico apresentado na Figura 3, elaborado com dados de 2020 do PRODES que apresenta o desmatamento acumulado ocorrido nos nove estados que formam a Amazônia Legal, totalizando $457.474 \mathrm{~km}^{2}$ no período de 1988 a 2020 (Brasil, 2020). 
Figura 3: Taxas de desmatamento por estado na Amazônia Legal - 1988/2020.

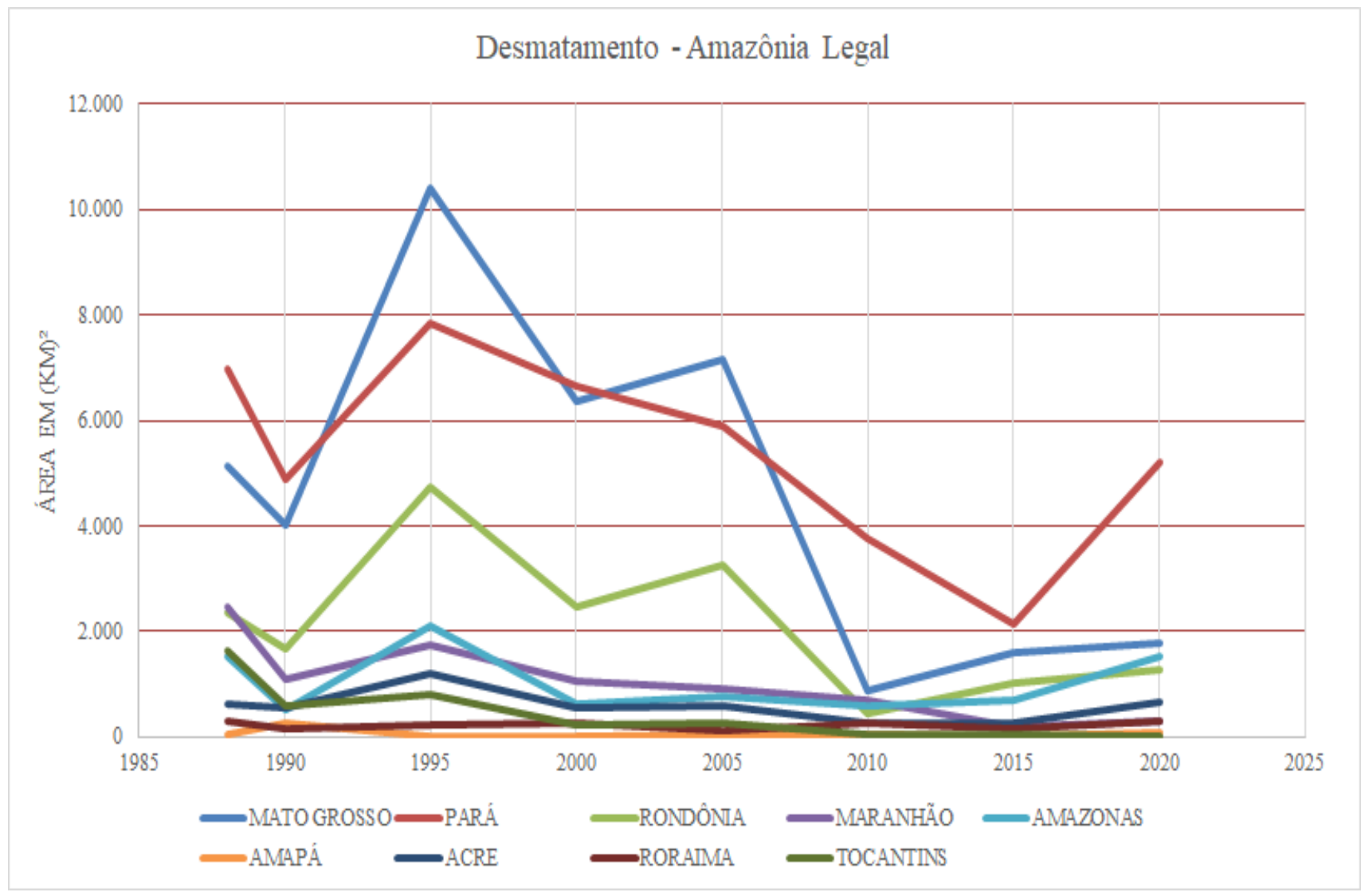

Fonte: Plataforma Terrabrasilis/PRODES (Brasil, 2020).

Nos dados apresentados no gráfico, é possível verificar a liderança do Pará e Mato Grosso no ranking do desmatamento acumulado computado pelo PRODES, nos últimos 33 anos. Também se sobressai que o pico em $\mathrm{km}^{2}$ ocorre até o ano de 1995, embora tenha sequência posteriormente.

No ano de 1996, diante da dramática situação de desmatamento na Amazônia veiculada nacional e internacionalmente, é estabelecida a Medida Provisória no 1.511, de 22 de agosto de 1996 (Brasil, 1996), pelo então Presidente Fernando Henrique Cardoso. Na Medida Provisória, a área de reserva legal foi ampliada de 50\% a 80\%, em uma tentativa de limitar o intenso processo de degradação do bioma, porém sem conseguir freá-lo.

No que se refere ao desmatamento acumulado, a Tabela 1 ratifica a liderança desses estados no arco do desmatamento nas últimas quatro décadas. Atualmente, os dados registrados pelo Sistema de Deteç̧ão do Desmatamento em Tempo Real (DETER), do Instituto Nacional de Pesquisas Espaciais (INPE), alertaram sobre as áreas de desmatamento e degradação na Amazônia Legal, produz sinais diários de alteração na cobertura florestal para áreas maiores que três hectares $(0,03$ km²), tanto para áreas totalmente desmatadas como para aquelas em processo de degradação florestal (exploração de madeira, mineração, queimadas e outras) (Brasil, 2021).

O acumulado em 2021 foi $1.157 \mathrm{~km}^{2}$ contra $1.204 \mathrm{~km}^{2}$ no mesmo período de 2020 . Os especialistas alertam de que há "uma tendência de alta muito preocupante", tendo em vista a proximidade do período de seca, não só na Amazônia, mas também no Cerrado, que corresponde aos meses de inverno (Brasil, 2021). 
Tabela 1: Desmatamento acumulado - Estados da Amazônia Legal - Período entre 1988/2020

\begin{tabular}{llll}
\hline Ranking & Estado & Área $/ \mathrm{km}^{2}$ & Percentual \% \\
\hline $1^{\circ}$ & Pará & $157.667,00$ & 34.46 \\
\hline $2^{\circ}$ & Mato Grosso & $147.926,00$ & 32.34 \\
\hline $3^{\text {o }}$ & Rondônia & $62.936,00$ & 13.76 \\
\hline $4^{\text {o }}$ & Amazonas & $28.493,00$ & 6.23 \\
\hline $5^{\text {o }}$ & Maranhão & $25.707,00$ & 5.62 \\
\hline $6^{\circ}$ & Acre & $15.725,00$ & 3.44 \\
\hline $7^{\circ}$ & Tocantins & $8.727,00$ & 1.91 \\
\hline $8^{\circ}$ & Roraima & $8.597,00$ & 1.88 \\
\hline $9^{\circ}$ & Amapá & $1.696,00$ & 0,37 \\
\hline
\end{tabular}

Fonte: Plataforma Terrabrasilis/PRODES (Brasil, 2020).

Embora o governo federal alegue que vem executando ações de combate ao desmatamento como a Operação Verde Brasil 2, o Observatório do Clima (2021a), rede política formada por 63 organizações da sociedade civil, afirma que a alta no desmatamento desmente o atual mandatário presidencial, que comemorou a queda de cerca de $15 \%$ nos alertas de incêndios florestais, verificados entre agosto de 2020 e abril de 2021, como sendo resultado da ação do Exército na Amazônia.

No mês de abril de 2021, a Amazônia perdeu $581 \mathrm{~km}^{2}$ de sua cobertura vegetal. O Pará liderou, mais uma vez, o ranking com maior área sob alerta de desmatamento de $211 \mathrm{~km}^{2}$, o que equivale a $36 \%$ do total registrado. Na sequência, aparecem o Amazonas (175 km²), Mato Grosso $\left(117 \mathrm{~km}^{2}\right)$, Rondônia $\left(50 \mathrm{~km}^{2}\right)$, Roraima $\left(20 \mathrm{~km}^{2}\right)$, Maranhão $\left(4 \mathrm{~km}{ }^{2}\right)$ e o Acre com 3 km². O Amapá e o Tocantins não tiveram áreas sob alerta de desmatamento (Brasil, 2021).

O desmatamento em larga escala diminui a capacidade da floresta de regular padrões de chuva e, com menos árvores, haverá menos umidade no ar e menos chuvas. Assim sendo, automaticamente menor produção agrícola, colocando os sistemas agrícolas do país em perigo, uma vez que o mercado terá que se adaptar ampliando profundamente a incerteza econômica em relação à incerteza hidrológica (Leite-Filho, Soares-Filho, Davis, et al., 2021).

$\mathrm{O}$ avanço do desmatamento e a redução da disponibilidade de água impactam a produtividade do agronegócio brasileiro, gerando perdas. Muitos produtores ainda não se deram conta disso e, em muitos casos, por desconhecimento da função da floresta na regulação dos regimes de chuvas, ou simplesmente praticando o negacionismo à ciência. A única forma de amenizar os prejuízos, que vêm sendo gerados ao agronegócio, será admitir a necessidade de políticas nacionais efetivas de controle e combate do desmatamento na Amazônia (Leite-Filho, Soares-Filho, Davis, et al., 2021).

A pecuária bovina é a atividade mais fortemente correlacionada com desmatamento na Amazônia Legal, conforme já sinalizado. A pecuária está presente tanto nas pequenas propriedades quanto nas grandes e tem se expandido quase continuamente em toda a história recente da ocupação da região (Rivero et al., 2009). A pecuária avança até mesmo nas reservas extrativistas que foram criadas para manter as florestas por meio do apoio às populações tradicionais de seringueiros e coletores de castanha-do-pará, substituindo a economia baseada em produtos florestais não madeireiros (Fearnside, 2020).

Desmatamento e expansão da pecuária se relacionam fortemente com o aumento nas exportações de carne no Brasil, nas duas últimas décadas. Diversos foram os fatores que proporcionaram impulso às exportações de carne bovina brasileira: com a desvalorização da moeda brasileira (dólar em alta), o valor da carne atingiu índices abaixo do esperado pelo mercado 
nacional; o surgimento de doenças animais como a febre aftosa, a doença da "vaca louca" (Encefalopatia Espongiforme Bovina); e a gripe aviária, na Ásia e Europa. Desse modo, a busca de mercados externos e as exportações foram ampliadas consideravelmente (Kaimowitz, et al., 2004).

Se recuarmos no tempo, verificaremos que, além dos fatores expostos, os múltiplos mecanismos fiscais (doações e renúncia fiscal) e os créditos implementados durante o período do "milagre econômico", pelos planos de desenvolvimento da Amazônia para a pecuária (1970 /1980), permitiram a aquisição de terras a baixos preços, bem como facilitaram grandes investimentos em novos e modernos matadouros e frigoríficos e laticínios, tornando a pecuária lucrativa aos grandes grupos do setor (Fearnside, 2020).

Outro fator impactante ao processo de pecuarização da terra na Amazônia foi a internacionalização das empresas de carne. Esse processo teve início em 2005, com a política de apoio às empresas brasileiras eleitas pelo governo para serem transformadas em grandes multinacionais. Assim, dois terços dos recursos do Banco Nacional de Desenvolvimento Econômico e Social (BNDES), com empréstimos a juros baixos, fomentaram o crescimento de frigoríficos como a JBS, a Marfrig e a Bertin que figuravam entre os três maiores beneficiários da política. Portanto, o governo brasileiro tem apoiado a expansão dos exportadores globais de carne e couro na região amazônica. Essa situação deixa evidente o conflito de interesses para as intenções do governo brasileiro de reduzir o desmatamento (Greenpeace, 2009).

O desmatamento e a extração ilegal de madeira são predominantes em grande parte do território amazônico. A exploração madeireira sustentável e com planos de manejo, no entanto, nunca foi prioritária e nem mesmo teve subsídios como as atividades agropecuárias, daí a razão de que a floresta em pé e produtiva pouco interessa ao modelo de política econômica. Pressupõe-se que as áreas desmatadas são utilizadas, inicialmente, para a pecuária extensiva e, subsequentemente, à agricultura migratória, visto que dos 38,7\% do território brasileiro ocupado pelo setor agrícola, metade está voltada para pastos, segundo dados da Empresa Brasileira de Pesquisa Agropecuária (Embrapa). A pecuária utiliza mais de 200 milhões de hectares de terras, dos quais 48 milhões na Amazônia, distribuídas em propriedades que variam de alguns poucos até dezenas de milhares de hectares (Fearnside, 2020).

Os dados da Produção da Pecuária Municipal (PPM) foram editados pelo Ministério da Agricultura até 1970; a partir de 1973, passou a ser editado pelo IBGE (Decreto-Lei no 73.482, de 17/01/1974). A Figura 4 apresenta os referidos dados do período de 1985 a 2020, que mostram essa expansão em grande proporção do rebanho de gado bovino nos estados que formam a Amazônia Legal. Mato Grosso e Pará lideram a produtividade do gado bovino por 35 anos consecutivos. Esse aumento considerável em números de cabeças bovinas corrobora para explicar a finalidade do desmatamento na ocupação e no uso do solo destinados à pecuária na Amazônia. 
Figura 4: Número de bovinos por estado na Amazônia Legal - 1985/2020 (gráfico / tabela).

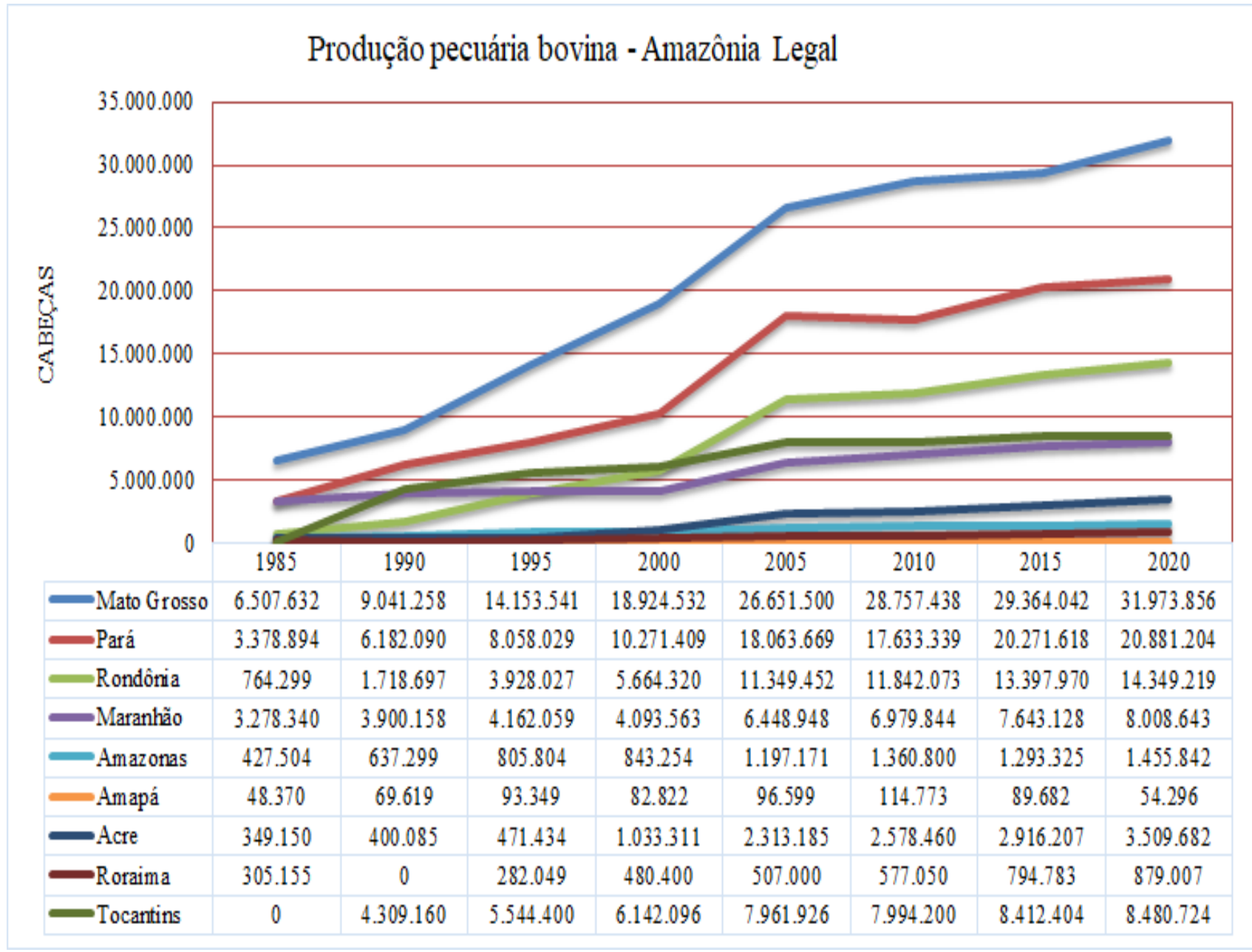

* 1990 - Não computados os dados ao Estado de Roraima.

** O Estado de Tocantins foi criado em 05 de outubro de 1988 (Artigo 13ㅇ - Ato Das Disposições/ Constituição Federal).

Fonte: Autores, Produção da Pecuária Municipal (IBGE, 2021).

No Brasil, dentre as commodities exportadas, a carne bovina destaca-se como um dos produtos com representatividade de $8,5 \%$ no PIB total do país e de 4,6\% das exportações brasileiras, somando 618,50 bilhões de reais, configurando em primeiro lugar nas exportações de carne bovina em 2019. Em 2020, a exportação de carne in natura foi de 1.724.404 toneladas, e as receitas alcançaram o total de US \$7.446.886 milhões, conforme dados da série histórica das exportações de carne bovina o site da Associação Brasileira das Indústrias Exportadoras de Carne (ABIEC) (2021), associação formada por 32 grandes empresas do setor de exportação da carne.

No ano de 2020, segundo dados da Pesquisa Trimestral do Abate de Animais do IBGE, o Brasil abateu 17.322.226 cabeças bovinas. Desse total, somente os estados da Amazônia Legal participaram com aproximadamente 67\% do abate, ou seja, com 11.600.620 cabeças (Tabela 2), o que mostra a amplitude do mercado de carne nesses estados.

As dez empresas que concentram 59\% da capacidade total de abate dos frigoríficos ativos na Amazônia Legal são a JBS, Marfrig Global Foods, Minerva Alimentos, Mercúrio Alimentos, Masterboi, Vale Grande, Frigol, Frigon, Fribal e Cooperativa dos Produtores de Carne e Derivados de Gurupi. Os $41 \%$ restantes estão distribuídos entre empresas menores (Barreto et al. 2017). 
Tabela 2: Abate bovino nos Estados da Amazônia Legal/ 2020.

\begin{tabular}{cc}
\hline Estados & Quantidade cabeças abatidas/2020 \\
\hline Mato Grosso & 5.076 .288 \\
\hline Pará & 2.210 .994 \\
\hline Rondônia & 2.179 .717 \\
\hline Tocantins & 894.811 \\
\hline Maranhão & 566.989 \\
\hline Acre & 372.495 \\
\hline Amazonas & 211.634 \\
\hline Roraima & 87.692 \\
\hline Amapá & $*$ \\
\hline
\end{tabular}

* Valor não informado. Fonte: Autores, (IBGE-SIDRA, 2021).

O volume dos negócios desse setor tem induzido o Estado brasileiro a criar uma série de medidas visando maior ganho de competitividade frente ao mercado externo. Em 2002, o Ministério da Agricultura, Pecuária e Abastecimento (MAPA), criou o Sistema Brasileiro de Identificação e Certificação de Origem Bovina e Bubalina (SISBOV). Esse sistema visa à identificação, o registro e monitoramento individual de todos os bovinos e bubalinos nascidos no Brasil ou importados, assim como estabelece a obrigação de registro das propriedades no cadastro nacional do Estabelecimento Rural Cadastrado (ERC) e recebe o certificado de Estabelecimento Rural Aprovado (ERAS). A partir de 2005, o cadastro passou a ser obrigatório apenas para produtores exportadores.

Em 2006, foi estabelecido o Sistema Brasileiro de Inspeção de Produtos de Origem Animal (SISBI), o qual faz parte do Sistema Unificado de Atenção à Sanidade Agropecuária (SUASA). A emissão das Guias de Trânsito Animal (GTA) é realizada pelas agências estaduais de controle sanitário animal e são obrigatórias. Estados e municípios chegaram a estruturar os seus serviços de inspeção; porém, em termos gerais, eles ainda estão longe de prestar a fiscalização necessária.

Entretanto, devido às evidências de estabelecimentos que burlavam as medidas de controle impostos pelo governo federal, em 2009, o Ministério Público Federal (MPF) e o Instituto Brasileiro do Meio Ambiente e dos Recursos Naturais Renováveis (Ibama) processaram frigoríficos no estado do Pará que compravam de fazendas embargadas por desmatamento ilegal. O Ministério Público do Estado ameaçou processar empresas, como supermercados e indústrias de couro, que adquirissem matéria-prima desses frigoríficos, e aplicou multas que totalizaram dois bilhões de reais (Pegurier \& Barreto, 2019).

Em consequência da repercussão da campanha do Greenpeace denominada Farra do Boi, que advertia contra o uso de matérias-primas advindas de gado de desmatamento na Amazônia, o MPF propôs o acordo conhecido como TAC da Carne. Assim, alguns dos grandes frigoríficos cederam e assinaram o documento, que estabelecia que os compradores se tornariam responsáveis pela fiscalização dos pecuaristas que eram seus fornecedores. O TAC apresentava as exigências como:

A cada transação, os frigoríficos deveriam garantir que o produtor de quem compravam cumprisse cinco quesitos: não constasse da lista de embargos e multas ambientais do Ibama; não possuísse áreas desmatadas detectadas pelo Instituto Nacional de Pesquisas Espaciais; tivesse realizado seu Cadastro Ambiental Rural (CAR); suas terras não se sobrepusesse a unidades de conservação ou terras indígenas; e também não constasse na lista de exploradores de trabalho escravo do Ministério do Trabalho (Pegurier \& Barreto, 2019, p. 18). 
Entretanto, diversas são as formas de burlar tais exigências, que vão desde a compra de bezerros para a engorda, que vêm de pequenas e médias propriedades não legalizadas, atuando como fornecedores indiretos, propriedades que trabalham com os sistemas de cria - quando o bezerro ainda é amamentado pela mãe - e recria - fase iniciada logo após o desmame, por volta dos sete meses de idade, conforme Barreto et al. (2017). Nem todos os frigoríficos que atuam na Amazônia assinaram o compromisso de monitoramento.

Na Amazônia Legal, existem 157 frigoríficos com registro no Sistema de Inspeção Federal (SIF) e no Sistema de Inspeção Estadual (SIE). Os frigoríficos registrados no Sistema de Inspeção Estadual (SIE) podem vender somente nos estados onde se localizam e os registrados no Sistema de Inspeção Federal (SIF) podem vender para todo o país e, se atenderem critérios adicionais, podem exportar (IBGE, 2021).

Desses 157 frigoríficos, 128 estavam ativos (82\%) e 29 inativos em 2016. Além disso, 63 frigoríficos registrados SIF (dos 128 ativos) pertenciam a 38 empresas que assinaram o acordo, o que representa $91 \%$ da capacidade de abate. Os que são registrados no SIE somaram apenas 9\% dessa capacidade. Assim, dos 79 frigoríficos com TAC, 63 estão ativos e 16 não; dos 78 sem TAC, 65 estão ativos e 13 não. Esse sistema de rastreabilidade vem se mostrando ineficiente em garantir que a produção de carne bovina está sendo executada em áreas sem desmatamento ilegal. Vale lembrar que o fato de o frigorífico não ter assinado o TAC não significa que não realiza exportação de carne bovina (Pegurier \& Barreto, 2019).

No Brasil, existem diversos órgãos governamentais e leis para controle, monitoramento, planejamento ambiental e econômico, especialmente para o combate ao desmatamento. O Código Florestal (Lei Federal $\mathrm{n}^{\circ}$ 12.651, de 25 de maio de 2012) é o principal marco regulatório para a gestão de florestas e demais formas de vegetação em propriedades rurais no Brasil. A Lei determina quais áreas devem ser protegidas e preservadas e quais são passíveis de uso rural. A implantação efetiva da lei é fundamental para conciliar o aprimoramento e expansão da produção agropecuária com a conservação ambiental (ICV, 2019).

O atual Código Florestal trouxe mudanças, como a criação do Cadastro Ambiental Rural (CAR), no âmbito do Sistema Nacional de Informação sobre Meio Ambiente (SINIMA), obrigatório para todos os imóveis, com a finalidade de integrar as informações ambientais das propriedades e posses rurais na base de dados do Ministério do Meio Ambiente (Brasil, 2012a).

Embora a maior parte dos estados não tenha colocado em prática a referida Lei, já ocorrem diversas contradições, dentre elas, a sobreposição de diversas áreas, por não exigir documento que comprove o domínio do imóvel e se basear em informações prestadas pelo próprio requerente, sem prazo para verificação pelo Estado, o que abre caminho para impactos ambientais e o acirramento de conflitos fundiários em Terras Indígenas (TI), conforme o relatório Conflitos no campo, de 2020, da Comissão Pastoral da Terra (CPT).

Essa situação beneficia, em sua maioria, grandes imóveis rurais, aponta a nota técnica assinada em conjunto pela Federação dos Povos e Organizações Indígenas de Mato Grosso (FEPOIMT), Instituto Centro de Vida (ICV), Operação Amazônia Nativa (OPAN) e International Rivers (ICV, 2020). Conforme dados do Conselho Indigenista Missionário (CIMI), organismo vinculado à Conferência Nacional dos Bispos do Brasil (CNBB), de janeiro a setembro de 2019, os ataques e invasões às terras indígenas no Brasil subiram mais de $40 \%$ em relação ao ano anterior. Os ataques são atribuídos a grileiros, garimpeiros e pessoas envolvidas com a extração ilegal de madeira (Costa, 2020).

As ameaças vêm sendo constantes e podem se ampliar ainda mais. Em documento assinado por 254 organizações não governamentais, solicita-se a paralisação dos debates sobre o Projeto de Lei, PL nº 191/2020, do Governo Federal, que defende a mineração em terras indígenas, e o PL no 2633/2020 sinaliza para a regularização de áreas já ocupadas, afrouxando a fiscalização delas. Segundo a Comissão Pastoral da Terra:

A MP 759/16 convertida na Lei 13.465/17, torna regra geral a regularização fundiária em favor de médios e grandes 
proprietários, invertendo toda a lógica constitucional de destinação prioritária das terras públicas para categorias fundiárias mais protetivas social e ambientalmente, como para os assentamentos de reforma agrária (art. 188 da Constituição Federal - CF), a proteção de ecossistemas (art. 225, §5 da CF) e dos modos de vida associados a sua preservação, como os territórios indígenas (art. 231 da CF), das comunidades quilombolas (art. 68 do Ato das Disposições Constitucionais Transitórias - ADCT) e comunidades tradicionais (art. 215, art. 216 da CF e Decretos 5051/0432 - Convenção 169 e Decreto 6.040/07) (CPT, 2020, p. 146).

O PL n 510/2021 trata da "MP da Grilagem" e/ou (MP 759/16 - Lei n 13.465/17), remodelada, que tramita no Senado, assim como da regularização de áreas de até 2.500 hectares sem a necessidade de uma vistoria prévia pelo Instituto Nacional de Colonização e Reforma Agrária (INCRA). Se aprovada, irá favorecer médios e grandes proprietários, o que poderá promover a extinção de assentamentos rurais e ameaçar populações tradicionais e agroextrativistas, visto que, na prática, não será necessário constatar se há algum conflito naquela área que impeça sua regularização ou se regras ambientais estão sendo infringidas (Benites, 2021).

\subsection{Expansão pecuária, desmatamento e recursos hídricos no norte do Mato Grosso}

Ao se deslocar para o recorte territorial do norte do Mato Grosso, observa-se que a transformação socioprodutiva inscreve profunda relação com a intervenção estatal, principalmente a partir da década de 1970. O controle da terra, a colonização privada, a política de migração induzida e financiada pelo Estado e o incentivo a grandes empreendimentos agropecuários asseguraram o desenvolvimento da fronteira urbana que funcionou como recurso estratégico para a rápida ocupação da Amazônia (Becker, 2005).

Conforme relata o geógrafo Ariovaldo Umbelino de Oliveira, “as rodovias que ligam Cuiabá aos recantos mais afastados do Estado foram as principais responsáveis por essa verdadeira 'invasão' verificada no território amazônico". Conhecida como a "estrada dos colonos", a rodovia Cuiabá-Santarém (BR-163) é a espinha dorsal do desenvolvimento do norte de Mato Grosso. No seu entorno, desenvolveram-se importantes cidades, tais como Nova Mutum, Lucas do Rio Verde, Sorriso, Sinop, Colíder, Nova Canaã, Alta Floresta, dentre outras. Nesses locais registraram-se quase todos os projetos de assentamento de colonos no norte de Mato Grosso (Oliveira, 2005).

Nos dias que correm, as mudanças no uso da terra e a expansão urbana estão entre os vetores de degradação que atuam com maior intensidade. O crescimento da pecuária e da agricultura configura-se como o maior responsável pelas mudanças no uso da terra, uma vez que intensifica o processo de abertura das áreas com a supressão das florestas, subordinado à modernização autoritária e conservadora do território do país. A busca do aumento de produtividade via utilização de práticas insustentáveis tem raízes históricas, culturais e sociais, que remontam ao início da colonização privada na década de 1970 (Fearnside, 2005).

Nos anos iniciais de abertura das áreas territoriais pertencentes aos municípios fundados na época, ainda se encontravam extensas e preservadas. Apenas os municípios de Alta Floresta e Colíder se destacavam com áreas maiores destinadas a pastagens; as destinadas ao uso agrícola se localizavam em Marcelândia, Nova Santa Helena e Itaúba.

Além da exploração e extração vegetal, esse período trouxe a marca da presença do garimpo em locais onde a agricultura desenvolvida era a de subsistência, em grande maioria, situação que levou a atração da mão-de-obra familiar em busca de atividades laborais e renda no garimpo do ouro, dadas as dificuldades enfrentadas para prosperar a agricultura familiar (Pinheiro, Bampi, Silva, 2020).

A Tabela 3 apresenta os dados do uso e da ocupação do solo relativos à floresta, pastagens e agricultura das respectivas áreas territoriais dos municípios pertencentes à macrorregião Norte (2) no ano de 1985 e 2019. 
Tabela 3: Uso e cobertura do solo de floresta, pastagens e agricultura dos municípios da Macrorregião Norte (2) referente aos anos de 1985/2019.

\begin{tabular}{|c|c|c|c|c|c|c|c|}
\hline $\begin{array}{l}\text { Município } \\
\text { /Ano/ha }\end{array}$ & $\begin{array}{l}\text { Unidade } \\
\text { territorial }\end{array}$ & $\begin{array}{l}1985 \\
\text { Floresta }\end{array}$ & $\begin{array}{l}1985 \\
\text { Pastagem }\end{array}$ & $\begin{array}{l}1985 \\
\text { Agrícola }\end{array}$ & $\begin{array}{l}2019 \\
\text { Floresta }\end{array}$ & $\begin{array}{l}2019 \\
\text { Pastagem }\end{array}$ & $\begin{array}{l}2019 \\
\text { Agrícola }\end{array}$ \\
\hline Alta Floresta & $895.599,9$ & $781.244,6$ & $107.082,84$ & 277,16 & $445.106,59$ & $412.546,18$ & $26.097,52$ \\
\hline Apiacás & $2.048 .902,4$ & $1.989 .689,3$ & $13.788,46$ & $*$ & $1.807 .511,25$ & $198.122,16$ & $1.202,61$ \\
\hline Carlinda & 242.1788 & $212.282,0$ & $26.107,91$ & 6,78 & $78.787,27$ & $147.028,63$ & $11.886,11$ \\
\hline Colíder & $311.209,1$ & $182.584,9$ & $126.504,92$ & 207,68 & $80.943,09$ & $208.422,44$ & $16.993,53$ \\
\hline Guarantã do Norte & $472.528,1$ & $429.060,9$ & $34.774,30$ & $*$ & $227.033,44$ & $204.864,81$ & $14.883,15$ \\
\hline Itaúba & $451.790,9$ & $421.631,2$ & $27.026,27$ & 293,09 & $274.207,53$ & $101.675,16$ & $61.347,82$ \\
\hline Marcelândia & $1.228 .611,9$ & $1.168 .862,2$ & $52.110,55$ & 654,60 & $931.985,01$ & $198.850,50$ & $87.959,41$ \\
\hline Matupá & $522.827,2$ & $487.134,6$ & $32.072,95$ & 1,76 & $315.014,39$ & $158.166,94$ & $38.627,02$ \\
\hline Nova Monte Verde & $513.930,7$ & $495.253,8$ & $18.209,60$ & $*$ & $291.106,27$ & $219.157,63$ & $2.211,25$ \\
\hline Nova Bandeirantes & $955.666,1$ & $932.998,6$ & $9.746,16$ & $*$ & $590.977,72$ & $344.754,81$ & $1.463,44$ \\
\hline Nova Canaã do Norte & $595.309,9$ & $517.769,4$ & $67.881,54$ & 81,22 & $292.421,66$ & $239.533,49$ & $46.756,61$ \\
\hline Nova Guarita & $112.192,8$ & $87.620,1$ & $22.852,43$ & 4,40 & $21.850,09$ & $74.956,57$ & $13.079,47$ \\
\hline Nova Santa Helena & $238.581,9$ & $190.288,6$ & $46.804,07$ & 430,44 & $122.146,15$ & $81.740,80$ & $32.984,86$ \\
\hline Novo Mundo & $580.075,9$ & $564.663,5$ & $6.892,30$ & 1,32 & $315.304,38$ & $201.346,71$ & $39.941,88$ \\
\hline Paranaíta & $481.356,0$ & $439.273,5$ & $33.741,37$ & 78,20 & $239.795,38$ & $214.203,38$ & $8.097,06$ \\
\hline Peixoto de Azevedo & $1.443 .293,4$ & $1.331 .646,8$ & $53.246,61$ & $*$ & $1.043 .146,67$ & $304.972,51$ & $39.984,32$ \\
\hline Terra Nova do Norte & $239.973,6$ & $190.022,4$ & $52.867,68$ & 14,95 & $50.807,58$ & $171.922,55$ & $19.253,44$ \\
\hline
\end{tabular}

* Não apresenta dados de agricultura no ano. Fonte: Autores (IBGE/MapBiomas, 2020).

Em um período de 34 anos, os dados da tabela revelam a grande quantidade de hectares convertidos de floresta originária para áreas destinadas à inserção de forrageiras para pastagem bovina, evidenciando drástica mudança no uso do solo. A pecuária bovina regional, atividade muito forte e de grande proporção, está estabelecida em praticamente todos os municípios da macrorregião Norte (2) e é a atividade hegemônica. As áreas agrícolas em 2019 apresentaram maior desenvolvimento, o que mostra a entrada da cultura de grãos, a exemplo dos municípios de Marcelândia e Itaúba e o avanço da produção ao extremo norte mato-grossense. Há, nesse contexto, uma pressão de busca por terras a cada vez que o valor de grãos sobe no contexto internacional.

Os resultados encontrados nos dados de uso do solo mostram que o desmatamento aniquilou um grande percentual da floresta original da macrorregião Norte (2), nas últimas décadas. Milhões de hectares do bioma foram destinados a áreas de pastagens e/ou agrícolas. A Tabela 4 apresenta os dados em $\mathrm{km}^{2}$ e em percentuais (\%) referentes ao desmatamento acumulado nos últimos 12 anos dos municípios que formam a macrorregião Norte (2). 
Tabela 4: Desmatamento acumulado nos municípios da macrorregião Norte (2), período de 2008/2020.

\begin{tabular}{|c|c|c|c|c|c|c|c|c|c|c|c|c|c|c|c|}
\hline MUNICÍPIOS & 2008 & 2009 & 2010 & 2011 & 2012 & 2013 & 2014 & 2015 & 2016 & 2017 & 2018 & 2019 & 2020 & $\mathrm{Km}^{2}$ & $\%$ \\
\hline Alta Floresta & 15,15 & 7,13 & 2,82 & 5,72 & 1,55 & 6,97 & 9,66 & 9,21 & 8,74 & 11,93 & 8,63 & 14,95 & 17,14 & 119,6 & 0,13 \\
\hline Apiacás & 45,99 & 13,65 & 14,92 & 14,08 & 12,14 & 18,57 & 12,02 & 16,42 & 18,13 & 27,14 & 29,16 & 85,55 & 51,77 & 359,55 & 0,38 \\
\hline Carlinda & 3,95 & 0,22 & 0,3 & 0,75 & 0,14 & 4,38 & 1,56 & 2,43 & 5,06 & 2,31 & 2,42 & 2,1 & 1,6 & 27,22 & 0,03 \\
\hline Colíder & 9,43 & 2,5 & 0,88 & 1,19 & 1,99 & 1,61 & 1,98 & 15,05 & 2,79 & 4,21 & 3,59 & 8,38 & 5,76 & 59,38 & 0,06 \\
\hline $\begin{array}{l}\text { Guarantã do } \\
\text { Norte }\end{array}$ & 39,55 & 9,06 & 4,79 & 8,17 & 4,04 & 8,02 & 7,34 & 11,46 & 14,8 & 7,31 & 4,18 & 13,07 & 7,98 & 139,75 & 0,15 \\
\hline Itaúba & 40,96 & 1,67 & 2,45 & 7,85 & 2,05 & 4,49 & 24,44 & 61,73 & 19,38 & 17,93 & 20,64 & 27,16 & 13,36 & 244,1 & 0,25 \\
\hline Marcelândia & 177,11 & 3,38 & 5,86 & 20,74 & 12,7 & 36,69 & 35,05 & 44,72 & 55,38 & 47,72 & 22,27 & 96,29 & 112,02 & 669,93 & 0,71 \\
\hline Matupá & 75,45 & 9,66 & 9,51 & 31,06 & 13,91 & 17,24 & 19,02 & 15,89 & 19,25 & 8,93 & 5,91 & 22,02 & 19,42 & 267,29 & 0,28 \\
\hline $\begin{array}{c}\text { Nova } \\
\text { Bandeirantes }\end{array}$ & 125,1 & 52,51 & 17,11 & 48,44 & 33,88 & 63,07 & 70,15 & 36,44 & 81,85 & 48,89 & 60,21 & 124,05 & 50,82 & 812,52 & 0,86 \\
\hline $\begin{array}{c}\text { Nova Canaã do } \\
\text { Norte }\end{array}$ & 20,07 & 4,88 & 3,41 & 4,11 & 0,71 & 2,06 & 12,43 & 18,71 & 9,73 & 12,45 & 15,81 & 16,01 & 9,2 & 130,22 & 0,14 \\
\hline $\begin{array}{l}\text { Nova } \\
\text { Guarita }\end{array}$ & 3,24 & 0,08 & 0.35 & 1,28 & 1,07 & 1,69 & 1,57 & 2,33 & 1,68 & 2,22 & 2,64 & 4,31 & 1,3 & 23,75 & 0,03 \\
\hline $\begin{array}{c}\text { Nova Monte } \\
\text { Verde }\end{array}$ & 23,43 & 6,55 & 2,64 & 3,58 & 5,14 & 3,01 & 5,26 & 6,26 & 18,43 & 17,43 & 16,91 & 39,98 & 18,89 & 167,5 & 0,18 \\
\hline $\begin{array}{c}\text { Nova Santa } \\
\text { Helena }\end{array}$ & 16,88 & 3,7 & 1,21 & 4,01 & 3,21 & 5,21 & 4,15 & 1,85 & 2,39 & 3,46 & 2,67 & 5,46 & 9,96 & 64,17 & 0,07 \\
\hline Novo Mundo & 42,01 & 12,26 & 13,04 & 15,19 & 4,2 & 14 & 15,19 & 22,42 & 20,09 & 19,68 & 13,97 & 21,51 & 19,46 & 233,37 & 0,25 \\
\hline Paranaíta & 41,38 & 7,74 & 9,75 & 16,05 & 6,07 & 12,95 & 39,43 & 23,18 & 50,26 & 40,78 & 42,16 & 55,15 & 24,43 & 369,33 & 0,39 \\
\hline $\begin{array}{l}\text { Peixoto de } \\
\text { Azevedo }\end{array}$ & 66,96 & 23,84 & 21,99 & 55,41 & 38,91 & 51,34 & 23,27 & 36,62 & 33,7 & 39,51 & 23,58 & 53,85 & 63,62 & 532,7 & 0,56 \\
\hline $\begin{array}{c}\text { Terra Nova } \\
\text { do Norte }\end{array}$ & 22,26 & 11,62 & 4,8 & 4,58 & 4,44 & 7,68 & 3,53 & 2,22 & 6,51 & 4,32 & 4,91 & 7,18 & 1,9 & 85,96 & 0,09 \\
\hline
\end{tabular}

Fonte: Autores (Plataforma Terrabrasilis/PRODES) (Brasil, 2020).

O município de Nova Bandeirantes lidera, apresentando desmatamento acumulado com 812,52 km². Quanto aos dados relativos ao uso e à ocupação e ao número de cabeças bovinas, é possível verificar o aumento significativo das áreas destinadas à pecuária bovina. Em Marcelândia $\left(669,93 \mathrm{~km}^{2}\right)$, houve aumento de áreas destinadas à pecuária e atividades agrícolas. Nos municípios da mesma região, Peixoto de Azevedo (532,70 km²), Paranaíta $\left(369,33 \mathrm{~km}^{2}\right)$, Apiacás $(359,55$ km²), Matupá $\left(267,29 \mathrm{~km}^{2}\right)$ e Itaúba $\left(244,10 \mathrm{~km}^{2}\right)$, os dados mostram que, embora tenham aumentado as áreas agrícolas, em uma pequena proporção, as destinadas à pecuária predominaram nos municípios elencados.

Os dados da Figura 5 corroboram para demonstrar a transformação das áreas de floresta em pastagens, ao apresentar o crescimento da pecuária bovina na macrorregião Norte (2), nesses 34 anos. As áreas da macrorregião estão inseridas no bioma Amazônia e praticamente em todos os municípios destaca-se a pecuária como principal atividade econômica. Levando-se em conta a expansão da pecuária, deduz-se que a principal atividade econômica responde pelo desmatamento e pela consequente pressão sobre os recursos hídricos. 
Figura 5: Número de bovinos por municípios da Macrorregião Norte 2 (período de 1985 - 2019) (Gráfico/tabela).

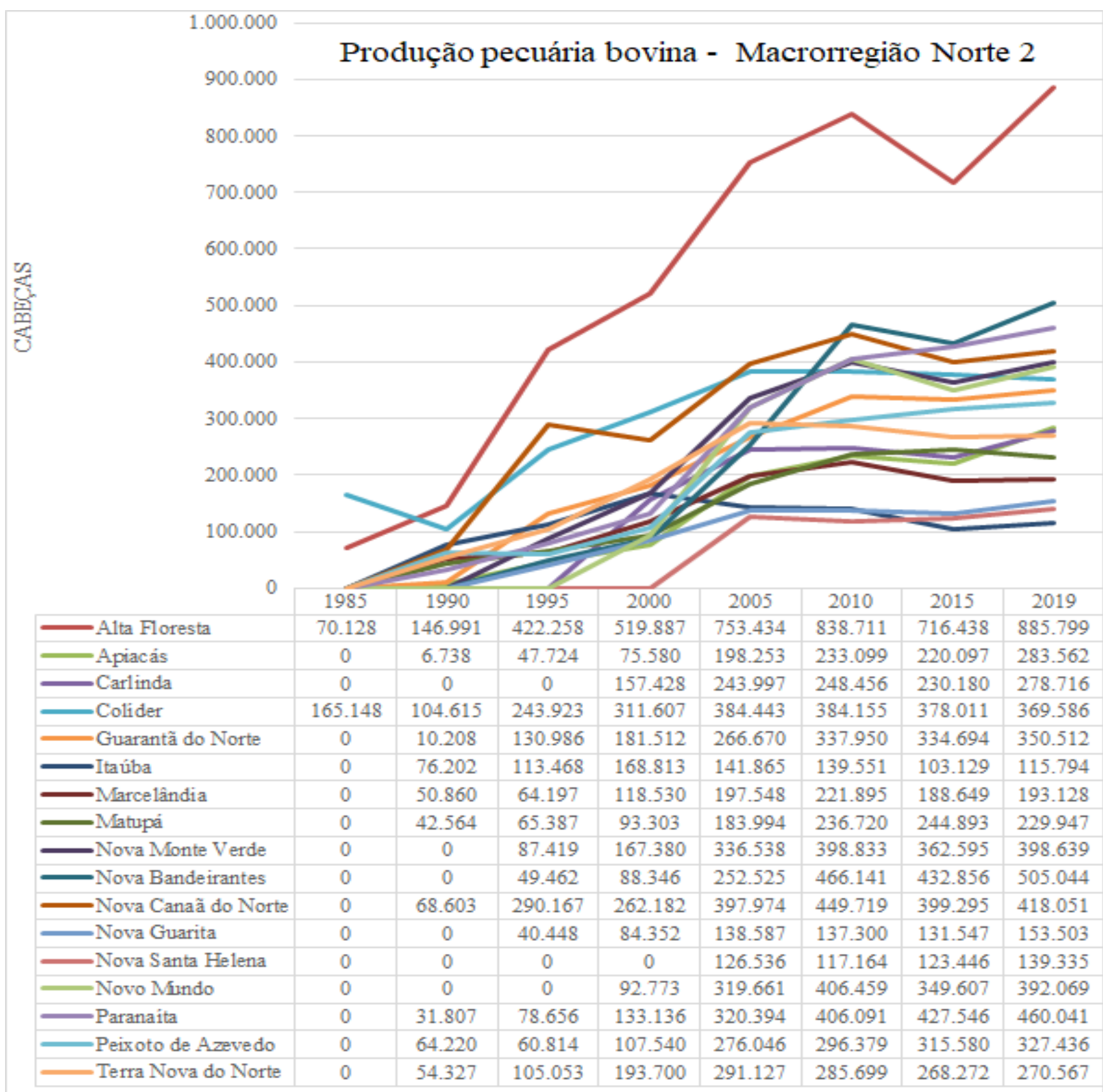

(0) * Dados não informados nos respectivos anos. Fonte: Autores (IBGE SIDRA, 2021).

O Instituto Mato-Grossense da Carne (IMAC) destaca que, no estado de Mato Grosso, houve aumento na produção, valorização da arroba e altas nas exportações da carne, abatendo 4.670 .395 cabeças de bovinos conforme dados do Ministério da Agricultura, Pecuária e Abastecimento (2020). O estado segue líder no ranking nacional de rebanhos bovinos com um quantitativo de 30,98 milhões de cabeças, e crescimento de 1,46\% em relação a 2019. Mato Grosso participou com aproximadamente $22 \%$ da carne bovina exportada pelo Brasil em 2019, liderando com um volume de 644,78 mil toneladas, conforme dados do Instituto Mato-Grossense de Economia Aplicada (IMEA). Dentre os principais mercados que respondem por $56 \%$ da exportação da carne bovina, estão a China e Hong Kong, sendo que a demanda chinesa aumentou em $67,8 \%$ a receita das exportações (IMAC, 2020).

Diante da expansão da pecuária e do desmatamento para fins de posição do país na divisão internacional do trabalho 
como produtor de commodities da cadeia grãos-carne, diversas pesquisas estudam o sistema climático e suas conexões com o uso do solo, revelando em profundidade os efeitos do desflorestamento no ciclo hidrológico, e como as diversas atividades antrópicas (principalmente a pecuária e a agricultura) vêm afetando a disponibilidade hídrica, o clima regional e local nas áreas de floresta.

O estudo Deforestation vs. changes in rainfall rates in the amazonian forest of northern Mato Grosso state (Debortoli, Rodrigues-Filho \& Dubreuil, 2011), apresenta a correlação entre o desmatamento e o uso do solo dos últimos 30 anos, como responsáveis diretos pela alteração do regime hidrológico na região norte mato-grossense. O diagnóstico se baseou em um conjunto de 30 estações meteorológicas para fins de coleta de índices de pluviosidade disponíveis no programa Hidroweb da Agência Nacional de Águas. Além disso, foram disponibilizadas imagens de sensoriamento remoto para analisar a presença de nuvens em uma área com floresta preservada (noroeste do MT) e em outra área antropizada ao longo do arco do desmatamento na rodovia BR-163.

A situação em tela foi alertada por diversos estudos quanto ao decréscimo de chuvas na Amazônia. O estudo supracitado apurou que:

As chuvas na área preservada foram mais bem distribuídas e em maior quantidade do que nas áreas próximas aos núcleos urbanos e eixos da malha viária (BR-163). Ocorreram mudanças nas precipitações de forma regional, o que aproxima a hipótese de que as áreas preservadas recebem maior precipitação por conta da ciclagem da água via evapotranspiração, [...] a conversão de florestas para agricultura, solo exposto e a queima de vegetação alteram significativamente o balanço de energia proveniente dos raios solares que atingem a terra, assim como a umidade presente no ar e a ciclagem de diversas partículas de elementos bioquímicos e biogeofísicos que compõem o ciclo hidrológico (Debortoli, Rodrigues-Filho \& Dubreuil, 2011, p. 2950).

Conforme os autores supracitados, os diagnósticos ainda evidenciaram diversas peculiaridades do ecossistema do bioma amazônico. À guisa de exemplificação, vale lembrar que o clima, temperatura e precipitação são regulados por períodos de seca e/ou chuvas, por fenômenos naturais como o La Niña, que pode ser tão chuvoso quanto o El Niño, pela redução dos fluxos de vapor que regulam a umidade relativa do ar, dentre outros fatores relacionados à destruição ambiental imposta via desmatamento de extensas áreas de floresta.

$\mathrm{O}$ aumento significativo das alterações ambientais, principalmente as ocasionadas pelo desmatamento de áreas destinadas à pecuária, e que futuramente tendem a ser revertidas em agrícolas, corrobora com a diminuição considerável do aporte de umidade proveniente da floresta, nos períodos de seca, e que garante a manutenção de rios e aquíferos (Dufour, Rodríguez-González \& Laslier, 2019).

Há ainda o perigo de extinção de espécies de flora e fauna, modificando significativamente a troca dos fluxos ecossistêmicos entre os biomas e afetando as atividades agrícolas e as populações urbanas e rurais. O uso da terra é um dos principais impulsionadores da degradação da vegetação ribeirinha (vegetação ripária) em escala local por meio de influências diretas do desmatamento e indiretas pela captação de água, poluição, entre outras (Pessi et al, 2019).

Segundo relata a pesquisadora Solange A. Arrolho da Silva (atual presidente do Comitê de Bacias do Baixo Teles Pires e estabelecida há décadas em Alta Floresta, conhecedora da história da transformação regional), por ocasião de interlocução em julho de 2021, sobre as atividades econômicas e a questão da água na região de estudo, há um enorme passivo das Áreas de Proteção Permanente (resguardadas por lei), deixando os bens naturais hídricos em situação de alta vulnerabilidade, bem como toda fauna originária (silvestre e aquática). Silva complementa salientando:

Para a fauna silvestre, principalmente no período de estiagem, há uma situação dramática, pois já não encontram fontes de dessedentação, tendo necessidade de migração a outros locais distantes, além de empecilhos à reprodução ou mesmo passam por situações que levam à morte. No contexto da ictiofauna o que se percebe é um problema de condições de alimentação e reprodução, gerando uma diminuição das espécies e, consequentemente, um desequilíbrio ecológico. 
Mesmo onde as APPs ainda permanecem, concomitantemente com a atividade pecuária, foram drasticamente alteradas e, segundo a investigadora, não conseguem cumprir sua função ecológica, ocasionando um grande problema à região no momento atual, que poderá ter um cenário de agravamento futuro, uma vez que não há indícios de processo de restauração ecológica em grande escala. Desse modo, os corpos hídricos foram afetados em relação à quantidade e à qualidade da água, a partir do desmatamento que atingiu as áreas de mata ciliar e seu entorno, bem como pela ação contínua do processo de pecuarização, impactando a biodiversidade, bem como a própria produção que necessita de água.

O modelo de uso do solo em áreas de pecuária sem manejo e práticas de conservação favorece os processos erosivos das terras superficiais por meio de procedimentos inadequados de manutenção, que afetam o escoamento superficial das águas por meio da compactação e diminuição das taxas de infiltração. Em consequência, altera-se o fluxo do curso por assoreamento e pela deposição de sedimentos, principalmente no período chuvoso, o que resulta em mudanças biogeoquímicas (Pessi et al, 2019).

A composição química dos corpos hídricos pode ser alterada diretamente pela adição de nutrientes e poluentes do solo, com efeitos prejudiciais sobre os ciclos dos nutrientes. O nitrogênio e o fósforo estão entre os principais poluentes em águas, pois levam à eutrofização e ao florescimento de algas, degenerando a qualidade da água, alterando as funções ecológicas (Souza et al., 2013; Dufour, Rodríguez-González \& Laslier, 2019).

Assim como, segundo os autores supracitados, a mata ciliar, no entorno dos corpos hídricos é o complexo de comunidades presentes na "zona ribeirinha", definida como "transição entre ecossistemas terrestres e aquáticos e distintos por gradientes em condições biofísicas, processos ecológicos e biota”. São áreas através das quais a hidrologia superficial e subterrânea conecta corpos d'água com suas terras altas adjacentes (Dufour, Rodríguez-González \& Laslier, 2019, p. 1170).

Além de fornecer sombra e temperaturas moderadas, aumenta a complexidade do habitat ribeirinho e a disponibilidade de alimentos, assim como fornece corredores para a movimentação da biota. Desse modo, a sua retirada ocasiona a perda da biodiversidade terrestre e aquática que faz parte da cadeia alimentar de muitas espécies, a exemplo dos peixes que fazem parte da dieta alimentar dos diversos povos (Souza et al., 2013).

As crises hídricas, nos diversos municípios da Amazônia norte mato-grossense, vêm sendo recorrentes nos últimos anos, situação um tanto contraditória, pois a região encontra-se na bacia hidrográfica amazônica formada por uma grande quantidade de nascentes e rios. Entretanto, Vandana Shiva (2006, p. 143) alerta que "a escassez e a abundância não são dadas pela natureza - são produtos das culturas de uso das águas, as quais desperdiçam ou destroem a frágil rede do ciclo da água, criam escassez até mesmo sob condições de abundância".

\section{Considerações Finais}

Diversos são os processos em curso que ameaçam a Floresta Amazônica, e um dos exemplos é a Iniciativa para a Integração da Infraestrutura Regional da América do Sul (IIRSA), iniciada no século XXI. O projeto compreende um conjunto de infraestruturas que visam transformar a Amazônia em um centro de transporte multimodal para implementar os corredores de exportação de grãos-carne em direção aos oceanos Atlântico e Pacífico. Ante a vasta quantidade de rios que atravessam vários estados da Amazônia Legal, a alta disponibilidade hídrica é um fator que posiciona a região como detentora de elevado potencial hidroelétrico. Além disso, os rios são parte integrante de diversos corredores de exportação de grãos e carne na forma de hidrovias que na última década tiveram seu uso intensificado.

Nessa direção e também a fim de legitimar as diversas ameaças de eliminar a proteção legal às florestas, configura-se uma rede política que atende aos interesses do agronegócio junto ao governo federal. Entre as ameaças está o PL nº 3729/2004. Depois da aprovação pela Câmara dos Deputados, o texto-base segue para apreciação do Senado e, se homologado, poderá extinguir o licenciamento ambiental no Brasil, mudando de forma irreversível a legislação, e aumentar ainda mais o 
desmatamento e as emissões de gases de efeito estufa do país.

O projeto, ao ser transformado em lei, poderá produzir recordes de desmatamento em série, pois elimina as restrições à derrubada da floresta para atividades agrícolas e de pecuária bovina, que irão demandar a execução de grandes obras de infraestrutura altamente devastadoras, como rodovias, hidrovias e hidrelétricas. Podemos destacar, por exemplo, o asfaltamento da rodovia que liga Porto Velho a Manaus (BR-319), obra que poderá vir a ser executada sem a necessidade de estudos de impacto ambiental, colocando cerca de metade do que resta da Floresta Amazônica à disposição para o desmatamento.

Ao analisarmos as contradições do capitalismo e seu desenvolvimento em áreas de fronteiras planetárias, como a da Amazônia, temos que apreender as formas de apropriação e de metabolismo social implementados nos diversos processos produtivos envolvendo a água, tais como a expansão da pecuária. A essência da existência da Amazônia é a sua floresta com os componentes de seu ecossistema (água, solo, subsolo, flora, fauna, clima, corpos hídricos, regime hidrológico, etc.). Assim sendo, as ações de destruição da floresta podem privar a Amazônia de sua existência.

Os processos de apropriação capitalista por meio da gestão por bacias hidrográficas, do uso intensivo de água em megaprojetos hidrelétricos e minerais, da produção agropecuária, das regulamentações do uso de água subterrânea e/ou superficiais, dos acordos sobre rios transfronteiriços da Amazônia, dos direitos de uso, dentre outros, vêm sendo colocados em prática na Amazônia, a partir da inserção singular do bioma na divisão internacional do trabalho. Assim, é imprescindível compreender a vulnerabilidade do bioma amazônico e a natureza ecossistêmica compartilhada com as comunidades locais. A degradação implementada pelas transformações das forças motrizes das mudanças climáticas globais e regionais interage de forma complexa no uso da terra e na exploração dos corpos hídricos.

O aumento do desmatamento por meio da agropecuária, principalmente nas APPs, promove uma série de impactos interconectados: 1) a erosão mecânica e química dos solos, processos de lixiviação e de exposição das encostas à erosão hídrica; 2) expansão do transporte de carga de sedimentos nos canais fluviais, produzindo o arrasto significativo de solo e o desbarrancamento das margens; 3 ) o alargamento da calha, o assoreamento de rios, diminuição da sua profundidade com o espraiamento das águas e a modificação de seu curso acompanhada de ampliação de enchentes.

Por fim, quanto maior for a perda de florestas, a inibição das chuvas poderá ser intensa, e dar lugar a um círculo vicioso de incêndios na floresta, redução de vapor d'água e elevação da emissão de fumaça na atmosfera, com a consequente supressão da precipitação pluvial. Nesse cenário, a exploração da agropecuária via desmatamento tem resultado em compactação do solo (encrostamento), erosão, assoreamento de rios, contaminação da água subterrânea e intensa perda da biodiversidade, e principalmente ocasiona a diminuição da água nos corpos hídricos, gerando a escassez hídrica.

\section{Agradecimentos}

A investigação contou com o apoio da Fundação de Amparo à Pesquisa do Estado de Mato Grosso - FAPEMAT e compreende resultados do projeto Estudo das formas de relação das atividades econômicas (pecuária e produção de grãos) com a água na Amazônia norte mato-grossense e suas consequências.

\section{Referências}

Associação Brasileira das Indústrias Exportadoras de Carne - ABIEC (2021). http://abiec.com.br/exportacoes/.

Aragón, L. E. (2018). A dimensão internacional da Amazônia: um aporte para sua interpretação/The international dimension of the Amazon: a contribution for its interpretation. Revista Nera, (42), 14-33. https://revista.fct.unesp.br/index.php/nera/article/view/5676/4254.

Amin, M. M. (2015). A Amazônia na geopolítica mundial dos recursos estratégicos do século XXI. Revista Crítica de Ciências Sociais, (107), 17-38. www.scielo.mec.pt/scielo.php?script=sci_arttext\&pid=S2182-74352015000200003\& lng=pt \&nrm=iso. 
Barreto, P., Pereira, R., Brandão Jr, A., \& Baima, S. (2017). Os frigoríficos vão ajudar a zerar o desmatamento da Amazônia. Imazon \& ICV. https://www.researchgate.net/profile/Paulo-Barreto-3/publication/318421566_Os_frigorificos_vao_ajudar_a_reduzir_o_desmatamento_da_ _ Amazonia /links/59899d73a6fdcc7562635a81/Os-frigorificos-vao-ajudar-a-reduzir-o-desmatamento-da-Amazonia.pdf.

Barros, F. G. N., \& Amin, M. M. (2007). A geopolítica da água e a bacia Amazônica brasileira. https://www.researchgate.net/profile/MarioHerreros/publication/228680474_A_GEOPOLITICA_DA_AGUA_EA_BACIA_AMAZONICA_BRASILEIRA/ links/55786cba08ae75363755b2ea/AGEOPOLITICA-DA-AGUA-EA-BACIA-AMAZONICA-BRASILEIRA.pdf.

Becker, B. K. (2005). Geopolítica da Amazônia. Estudos avançados, 19, 71-86. https://www.scielo.br/j/ea/a/54s4tSXRLqzF3KgB7qRTWdg/lang=pt.

Becker, B. K. (2010). Novas territorialidades na Amazônia: desafio às políticas públicas. Boletim do Museu Paraense Emílio Goeldi. Ciências Humanas, 5(1), 17-23. https://www.scielo.br/j/bgoeldi/a/d4vc5x595k5mJZfnMNNPKTs/?lang=pt.

Benites, A. (2021). Pressão leva Senado a jogar votação do ‘PL da Grilagem’ para semana que vem. https://brasil.elpais.com/brasil/2021-04-28/senado-pautavotacao-de-nova-versao-da-mp-da-grilagem-e-acende-alerta-sobre-boiada-antiambiental-preparada-pelo-congresso.html?rel=listapoyo

Brasil (1996). Medida Provisória n 1.511-1 DE 22 DE AGOSTO DE 1996. https://legislacao.presidencia.gov.br/atos/tipo=MPVnumero=1511-1ano=1996ato $=68 \mathrm{cg}$ XUE1EMJpWTdd9.

Brasil (2019). Agência Nacional de Águas (ANA). Conjuntura dos Recursos Hídricos: Informe 2019 /Agência Nacional de Águas. https://www.snirh.gov.br/portal/centrais-de-conteudos/conjuntura-dos-recursos-hidricos/conjuntura_informe_anual_2019-versao_web-0212-1.pdf/view.

Brasil (2020). Instituto Nacional de Pesquisas Espaciais - INPE. Terrabrasilis - Plataforma de dados geográficos. PRODES (Desmatamento Amazônia Legal). http://terrabrasilis.dpi.inpe.br/app/dashboard/deforestation/biomes/legal_amazon/rates.

Brasil (2021). Coordenação Geral De Observação Da Terra. Instituto Nacional de Pesquisas Espaciais - INPE. DETER. http://www.obt.inpe.br/OBT/assuntos/programas/amazonia/deter/deter.

Brasil (2021). Pesquisa Trimestral do Abate de Animais - $4^{\circ}$ trimestre 2020. https://sidra.ibge.gov.br/home/abate.

Bustamante, M. M. C., Keller, M., \& Silva, D. A. (2009). Sources and sinks of trace gases in Amazonia and the Cerrado. https://daac.ornl.gov/LBA/lbaconferencia/amazonia_global_change/21_Fontes_Sumidouros_Bustamante.pdf.

Comissão Pastoral da Terra - CPT (2020). Conflitos no Campo: Brasil/2020. https://www.cptnacional.org.br/.

Costa, C. (2020). 'A grande mentira verde': como a destruição da Amazônia vai além do desmatamento. www.bbc.com/portuguese/brasil-51317040.

da Silva, C. A. F., \& Bampi, A. C. (2020). Geopolítica e antiogeopolítica na Amazônia no neoliberalismo. https://www.agbbauru.org.br/publicacoes/rev ista/anoXXIV_3/agb_xxiv_3_web/agb_xxiv_3-29.pdf.

Davidson, E. A., \& Martinelli, L. A. (2009). Limitações de Nutrientes para a Regeneração de Floresta Secundária. https://daac.ornl.gov/LBA/lbaconferencia/amazonia_global_change /19_Limitacoes_de_Nutrientes_Davidson.pdf.

Davidson, E. A., de Araújo, A. C., Artaxo, P., Balch, J. K., Brown, I. F., Bustamante, M. M., \& Wofsy, S. C. (2012). The Amazon basin in transition. Nature, 481(7381), 321-328. https:// www.fs.fed.us/global/iitf/pubs/ja_iitf_2012_Davidson001.pdf.

Debortoli, N., Rodrigues Filho, S., \& Dubreuil, V. (2011). Deforestation vs. changes in rainfall rates in the amazonian forest of northern Mato Grosso state. In XV Simpósio Brasileiro de Sensoriamento Remoto-SBSR. INPE. 15, 2944-2951. https://www.researchgate.net/publication/263658284_Deforestation _vs_change s_in_rainfall_rates_in_the_amazonian_forest_of_northern_Mato_Grosso_state.

Souza, A. L. Fonseca, D. G., Liborio, R. A., \& Tanaka, M. O. (2013). Influence of riparian vegetation and forest structure on the water quality of rural loworder streams in SE Brazil. Forest Ecology and Management, 298, 12-18. https://www.sciencedirect.com/science/article/ abs/pii /S0378112713001163.

Dufour, S., Rodríguez-González, P. M., \& Laslier, M. (2019). Tracing the scientific trajectory of riparian vegetation studies: Main topics, approaches and needs in a globally changing world. Science of the total environment, 653, 1168-1185. https://www.sciencedirect.com/science/article/pii/ S0048969718342839.

Fearnside, P. M. (2005). Deforestation in Brazilian Amazonia: history, rates, and consequences. Conservation biology, 19(3), 680-688. https://doi.org/10.1111/j.1523-1739.2005.00697.x.

Fearnside, P. M. (2020). O desmatamento da Amazônia Brasileira: 11-Pecuária. Recuperado em 23 abril, 2021 de https://amazoniareal.com.br/odesmatamento-da-amazonia-brasileira-11-pecuaria/.

Franco da Silva, C. A., \& Bampi, A. C. (2019). Regional dynamics of the brazilian Amazon: between modernization and land conflicts. Cuadernos de Geografía: Revista Colombiana de Geografía, 28(2), 340-356. www.researchgate.net/publication/334716081_Regional_Dynamics_of_the_Bra zilian_Amazon_between_Modernization_and_Land_Conflicts.

Greenpeace (2009). Slaughtering the Amazon. https://www.greenpeace.org/usa/wp-content/uploads/legacy/ Global/usa/planet3/PDFs/slaughtering-theamazon-part-1.pdf.

Instituto Centro de Vida - ICV. (2019). Transparência Florestal Mato Grosso: do papel à prática: a implementação do Código Florestal pelos estados brasileiros. www.icv.org.br/drop/ wpcontent/uploads/2019/07/2019-transparenciaflorestal-CAR.pdf. Acesso em: 26 jun. 2020.

Instituto Brasileiro de Geografia e Estatística - IBGE. SIDRA (2021). Pesquisa da Pecuária Municipal - PPM. https://sidra.ibge.gov.br/tabela/3939.

Instituto Mato-Grossense de Economia Agropecuária - IMEA (2010). Mapa de Macrorregiões do IMEA. www.imea.com.br/imea-site/metodologia. 
Instituto Mato-Grossense da Carne - IMAC (2020). (imac.agr.br).

Kaimowitz, D., Mertens, B., Wunder, S., \& Pacheco, P. (2004). Hamburger connection fuels Amazon destruction. Bangor, Indonesia.Center for International Forest Research, 1-10. https:// www.researchgate.net/publication/263011651_Hamburger_Connection_Fuels_Amazon_ Destruction_Cattle_Ranching_and_Deforestation_in_Brazil's_Amazon.

Kohlhepp, G. (2002). Conflitos de interesse no ordenamento territorial da Amazônia brasileira. Estudos avançados, 16, 37-61. https://www.scielo.br/j/ea/a/mY9 cRhvB6MLvsHrYL8 gBs4F/?lang=pt.

Leite-Filho, A. T., Soares-Filho, B. S., Davis, J. L., Abrahão, G. M., \& Börner, J. (2021). Deforestation reduces rainfall and agricultural revenues in the Brazilian Amazon. Nature Communications, 12(1), 1-7. https:/www.nature.com/articles/s41467-021-22840-7

Lima, T. E (2020). Mapa de delimitação do Pan Amazônia, Amazônia Legal, Bacia Hidrográfica Amazônica. Laboratório de Pesquisa e Estudo em Geomorfologia Fluvial. UNEMAT. Cáceres.

Lima, T. E. (2020). Mapa de localização da Macrorregião Norte (2). Laboratório de Pesquisa e Estudo em Geomorfologia Fluvial. (LAPEGEOF). UNEMAT. Cáceres.

Ministério da Agricultura, Pecuária e Abastecimento (2020). Quantidade de Abate Estadual por Ano/Espécie. Dados Quantitativos de Abate sob a responsabilidade dos SIPAs/DFAs. sigsif.agricultura.gov.br/sigsif_cons/!ap_abate_estaduais_cons?p_select=SIM\&p_ano=2020\&p_id_especie=9.

Nobre, C. A., Sampaio, G., Borma, L. S., Castilla-Rubio, J. C., Silva, J. S., \& Cardoso, M. (2016). Land-use and climate change risks in the Amazon and the need of a novel sustainable development paradigm. Proceedings of the National Academy of Sciences, 113(39), 10759-10768. www.pnas.org/content/113/39/10759.full/.

Nobre, A. D. (2018). O futuro climático da Amazônia: relatório de avaliação científica. 2014. Edição ARA (Articulação Regional da Amazônia), CCST-INPE e Instituto de Pesquisas da Amazônia (INPA). http://www. ccst. inpe. br/o-futuro-climatico-da-amazonia-relatorio-de-avaliacao-cientifica-antonio-donatonobre/.

Observatório do Clima (2021a). Alta de desmatamento em abril desmente governo. https://www.oc.eco.br/alta-de-desmatamento-em-abril-desmente-governo/.

Observatório do Clima (2021b). Reação de organizações da sociedade civil ao fim do licenciamento ambiental. https://www.oc.eco.br/reacao-de-organizacoesda-sociedade-civil-ao-fim-do-licenciamento-ambiental-caixa-de-entrada/

Oliveira, A. U. D. (2005). BR-163 Cuiabá-Santarém: geopolítica, grilagem, violência e mundialização. Amazônia revelada: os descaminhos ao longo da BR163. Brasília: $C N P q, 67-183$. http://centrodememoria.cnpq.br/amazonia\%20revelada.pdf.

Oliveira, A. U. D. (2016). A fronteira amazônica mato-grossense: Grilagem, Corrupção e Violência. São Paulo: Iandé Editorial, 530 p. http://agraria.fflch.usp.br/sites/agraria.fflch.usp.br/files/A\%20FRONTEIRA\%20A MAZ\%C3\%94NICA\%20MATO\%20GROSSENSE.pdf.

Pegurier, E. Barreto. P. (Org.) (2019). Sob a pata do boi, como a Amazônia vira pasto. https://imazon.org.br/wp-content/uploads/2019/03/Sob_a_Pata_do_BoiLivro-Reportagens.pdf.

Pessi, D. D., Ereio, P. K. B., Alves, G. B. M., Martarello, A. P., \& Loverde-Oliveira, S. M. (2019). Qualidade da Cobertura Vegetal em Áreas de Preservação Permanente de Nascentes. Anuário do Instituto de Geociências, 41(3), 270-280. http://www.ppegeo.igc.usp.br/index.php/anigeo/article/view/13061/12655.

Pinheiro, J. A., Bampi, A. C., \& da Silva, C. A. F. (2020). O Projeto de Assentamento Conjunto Terranova I na borda Meridional da Amazônia matogrossense: efeitos territoriais da ocupação. InterEspaço: Revista de Geografia e Interdisciplinaridade.

Projeto Map Biomas - Coleção 5.0. (2020). Série Anual de Mapas de Cobertura e Uso de Solo do Brasil. http://mapbiomas.org.

Putti, A. (2019). Queimadas na Amazônia ganham repercussão na imprensa internacional. www.cartacapital.com.br/mundo/queimadas-na-amazoniaganhamrepercussao-na-imprensa-internacional/

Rivero, S., Almeida, O., Ávila, S., \& Oliveira, W. (2009). Pecuária e desmatamento: uma análise das principais causas diretas do desmatamento na Amazônia. Nova economia, 19, 41-66. https://www.scielo.br/j/neco/a/jZHjd9B8ZghY7tG9G7qchTk/?format=pdf\&lang=pt.

Scantimburgo, A. (2016). O avanço do agronegócio e o aumento dos conflitos pelo uso da água. Leituras de Economia Política, (24). www.eco.unicamp.br/images/arquivos/artigos/3490/Artigo2.pdf.

Shalders, A. (2019). Locais com mais queimadas também tiveram mais desmatamento, diz estudo. BBC News Brasil. www.bbc.com/portuguese/brasil49443561.

Silva, O. M. A. (2015). Pan-Amazônia: Visão Histórica, Perspectivas de Integração e Crescimento. Org. Osiris M. Araújo da Silva e Alfredo Kingo Oyama Homma. www.researchgate.net/publication/285578710_PanAmazonia_visao_historica_perspectivas_de_integracao_e_crescimento/link/56 5f435d08aeafc2aa ca45 7a/download.

Shiva, V. (2006). Guerras por água: privatização, poluição e lucro. Radical. https://dokumen.pub/qdownload/guerras-por-agua-privatizaao-poluiao-elucro.html.

Soares Filho, B. S. (1998). Modelagem da dinâmica de paisagem de uma região de fronteira de colonização amazônica. Escola Politécnica. São Paulo, Universidade de São Paulo. http://www.dpi.inpe.br/cursos/tutoriais/modelagem/referencias/tese_britaldo/capa.pdf

Walker, R. T., Simmons, C., Arima, E., Galván-Miyoshi, Y., Antunes, A., Waylen, M., \& Irigaray, M. (2019). Avoiding Amazonian catastrophes: prospects for conservation in the 21st century. One Earth, 1(2), 202-215. www.sciencedirect.com/science/article/pii/S2590332219300818. 